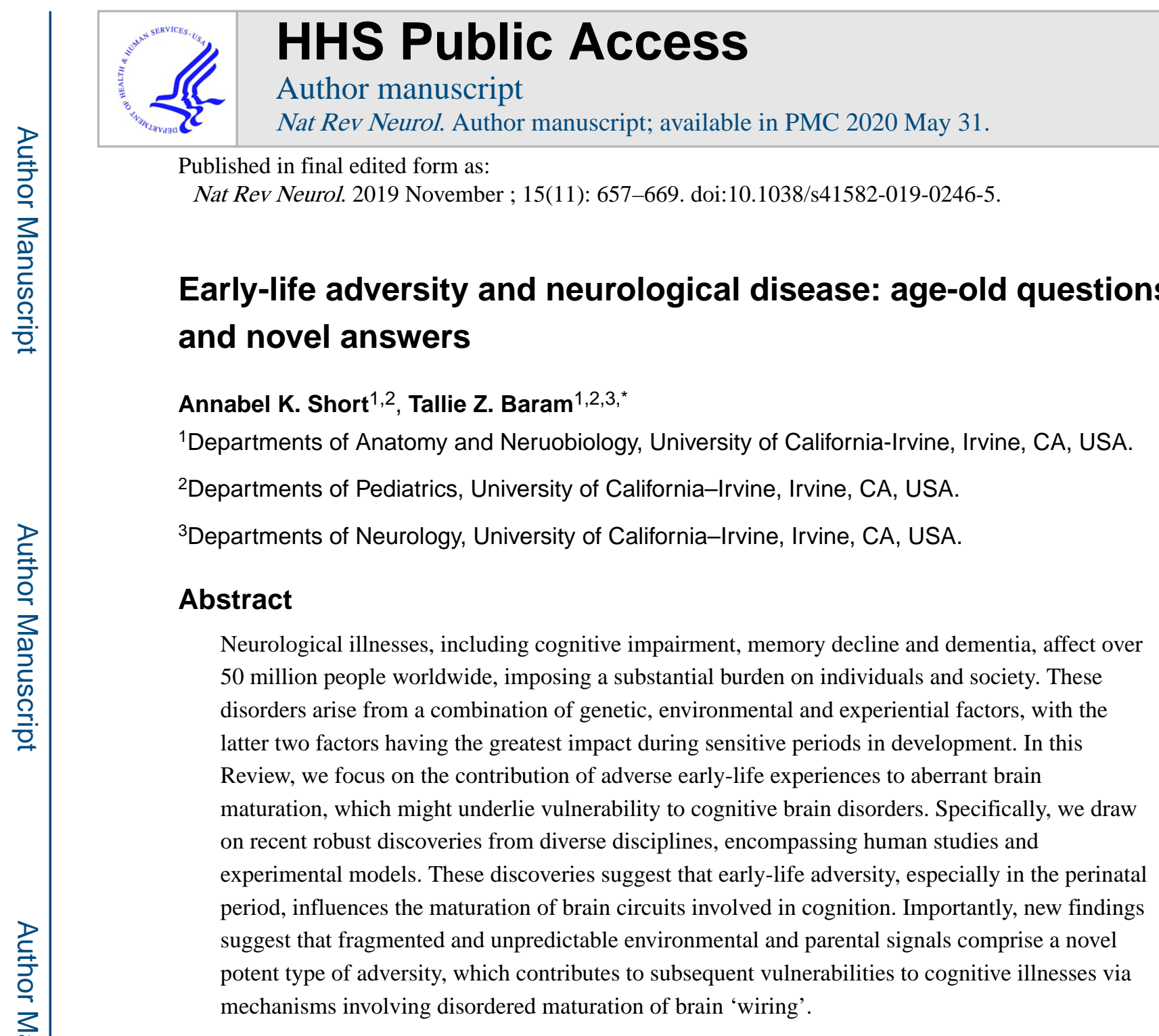

Neurological illnesses, including cognitive deficits and decline and dementia, are prevalent throughout the world, exerting an enormous toll in terms of both medical costs and loss of human potential ${ }^{1,2}$. Genetic factors have been shown to influence brain function throughout $\operatorname{life}^{3-5}$, and these factors, sometimes interacting with early-life experiences, account for a substantial proportion of the interindividual variance in both cognitive and emotional outcomes. Indeed, early-life experiences in themselves seem to play an important role in influencing cognitive outcomes ${ }^{6,7}$. The idea that early-life adversity influences cognitive and emotional health and disease throughout life is supported by strong epidemiological evidence, and the statistical relationship between early-life adversity and a variety of psychiatric disorders has been extensively documented and reviewed ${ }^{8-13}$. While

*tallie@uci.edu.

Author contributions

Both authors researched data for the article, wrote the article and reviewed and edited the manuscript before submission.

Competing interests

The authors declare no competing interests.

Publisher's note

Springer Nature remains neutral with regard to jurisdictional claims in published maps and institutional affiliations.

Reviewer information

Nature Reviews Neurology thanks R. Herringa and other anonymous reviewer(s) for their contribution to the peer 
acknowledging the frequent overlap between cognitive and emotional deficits ${ }^{14}$, in this Review we focus primarily on how early-life adversity could modulate cognitive functions across the lifespan, including memory problems in children ${ }^{10,15,16}$, cognitive decline during middle age ${ }^{17-22}$, and late-life dementia ${ }^{17,18,23}$. The types of adversity that have been implicated by studies on poor cognitive outcomes include low socioeconomic status (SES), war, famine, neglect and abuse, and being raised in an orphanage.

Large prospective and retrospective studies have provided support for the idea that early-life adversity promotes cognitive deficits ${ }^{24-31}$. Sophisticated analyses have advanced the recognition of the contribution of pre-existing genetic and societal factors to the association between conventional measures of adversity and cognitive outcomes. Cognitive indicators include poor school performance and reduced ability in specific tasks in childhood ${ }^{28,32-35}$ and reduced cognitive function during adult life. In this article, we describe some of the studies that have addressed the influence of environmental factors and experiences during sensitive periods early in life on vulnerability and resilience to cognitive pathology, address some of the caveats in these studies, and propose novel aspects of adverse early-life experiences that might influence brain maturation, leading to cognitive problems later in life (FIG. 1).

Prospective studies in humans can provide strong associations and generate causal and mechanistic hypotheses. However, it is difficult to account for potential confounders: children inherit genes from their parents, but parental characteristics might also influence the probability of an individual being born into an adverse situation, such as low SES.

Therefore, animal models in which genetic variables can be controlled are important to establish causality as well as to study mechanisms. Over the past few decades, dozens of articles have documented the memory impairments provoked by early-life adversity in rodents and non-human primates ${ }^{36-48}$. We focus on some of the salient findings in both nonhuman primates and rodent models, including evidence suggesting that early-life adversity in rodents impairs memory progressively during middle age and provokes premature memory senescence ${ }^{49,50}$. Although animal models are limited in their translatability to the clinical arena, taken together with robust human studies they reinforce the idea that certain aspects of early-life adversity affect cognitive function (and specifically memory) throughout life.

The mechanisms by which adverse early-life experiences influence the maturation of the brain to promote aberrant cognitive function are important to address. How do these influences endure, and how might they progress with age? We review established information as well as new and emerging evidence about the nature of adversity-induced signals that affect the maturation of cognitive brain functions, and we address potential mechanisms for the onset and persistence of these effects. We highlight the advent of technological advances that enable these fundamental questions to be better addressed, as well as the constructive iteration between the clinical questions and experimental animal models that is enabling the establishment of causality and mechanisms. 


\section{Studies in humans}

Human studies on early-life adversity have focused on low SES, including parental unemployment and education levels, and also on war, famine, neglect, abuse and institutional rearing. These studies have involved several approaches.

Large epidemiological studies have collected cohorts born or raised during specific epochs of adversity, then assessed cognitive outcomes compared with earlier-born or later-born cohorts. For example, the Dutch famine study addressed the effects of prenatal malnutrition resulting from starvation of the Dutch population during World War II ${ }^{51,52}$. In individuals who experienced this adversity prenatally, the investigators identified markers of accelerated brain ageing on MRI ${ }^{51}$, yet cognitive function during middle age was not influenced by the prenatal malnutrition ${ }^{52}$. A similar investigation conducted in China during the 'Great Leap Forward'- associated famine (1959-1961) identified cognitive disabilities in individuals who were exposed to prenatal malnutrition ${ }^{53}$. However, the effects were confined to men who were raised in rural areas, and memory per se was not affected ${ }^{53}$. Taken together, these studies provide only modest support for an effect ofprenatal malnutrition on later-life cognitive function.

Other types of studies examined cognitive outcome related to SES in both developing and developed countries. In developing countries such as Ethiopia, Peru and Vietnam, severe poverty as well as parental schooling were associated with poor school performance ${ }^{54}$. Other studies have capitalized on the large data sets that are common in Scandinavian health systems. These data sets go back for decades and enable examination of the relationship between early-life adversity and cognitive performance not only during childhood and adolescence but also during adulthood and middle age. For example, longitudinal observations of men from Eastern Finland identified SES as an important predictor of several cognitive measures during middle age ${ }^{17}$. However, as is often observed in human studies, other factors, including genetics, accounted for a substantial proportion of the variance in cognitive outcomes.

Several investigations have taken advantage of natural experiments and subsequent interventions. Prominent among these investigations are studies that monitored infants and children raised in institutions such as orphanages ${ }^{28,29,33-35,55}$. Because of the high infant to caregiver ratio, these infants were deprived of social and emotional interactions, although physical factors including nutrition were not generally deficient. The results of these studies were profound: lack of adequate individual emotional nurturing was associated with serious emotional and cognitive problems, including deficits in spatial working memory, visual recognition and associative learning $29,33,56$. In addition, in the randomized, controlled Bucharest adoption study, infants who were adopted by families at 2 years of age or earlier fared significantly better in terms of cognitive outcomes than those adopted later in life, suggesting that the first 2-3 years of life constitutes a critical period for the vulnerability to parental deprivation and the neuroplasticity that enables recovery 29,57 .

The concept of the disproportionate importance of adversity during the first years of life versus later in childhood and adolescence is supported by studies that examined the effects 
of poverty at various stages of a child's life ${ }^{58,59}$. Early poverty was a better predictor of later cognitive achievement than was poverty in middle or late childhood - an effect that is difficult to explain by genetics and, thus, supports an influence of the adversity itself ${ }^{58}$.

A number of large prospective studies addressing early-life adversity and cognitive function are ongoing in the USA, Europe and other parts of the world ${ }^{60-64}$. These studies generally enrol infants and children (or commence during prenatal life) ) $^{61,63,64}$ and follow their development until adolescence or adulthood. The studies centre on normative populations ${ }^{60,64}$ or on traumatized populations, such as those in inner-city Atlanta ${ }^{65}$. The studies vary in terms of demographics, ethnic backgrounds and outcome measures, and many include neuroimaging as well as hormonal and psychological batteries. Together, these studies should shed important light on the nature and timing of early-life adversities that have an impact on memory and other parameters of cognitive function, as well as on the underlying brain networks.

Several investigators have found an influence of early-life adversity on decline in cognitive function during middle age; ${ }^{17-20}$ however, this association has not been consistently observed $^{15,24,66-68}$. In addition, early-life poverty, stress and abuse have been linked to latelife dementia ${ }^{17,18,69-71}$.

An inherent difficulty in many human investigations is the inability to tease apart intrinsic (genetic) capabilities of the child from the effects of the environment. A further inherent complexity is the gene-environment interaction, whereby individuals with different genetic make-ups (for example, harbouring specific gene variants) might respond differently to early-life adversity. Genetic factors that have been implicated in these interactions include the Val-Met variants of the brain-derived neurotrophic factor (BDNF) gene, as well as variants of genes encoding the serotonin transporter, the corticotropin-releasing hormone receptor, the glucocorticoid receptor-interacting protein FKBP5 and the voltage-dependent calcium channel CaV1.2 (REFS $6,7,72-75)$.

Several research groups have used longitudinal approaches in an attempt to address the conundrum of pre-existing factors that antedate adversity. Among the most prominent are the Lothian Birth Cohort study ${ }^{21}$ and a study by Danese et al. ${ }^{76}$. In the Lothian study, children in the 1936 Aberdeen birth cohort underwent memory and cognitive testing at 11 years of age to establish their intellectual level, and their SES was also recorded. The same individuals were re-recruited in later life (for example, in their 60s and 70s) ${ }^{21}$, and childhood intelligence, social class, education, life-course social mobility, memory test performance and memory decline in late life were all assessed. Higher SES and intelligence during childhood predicted better cognitive performance later in life. The trajectory of memory decline was steeper in individuals who had received less education, and this relationship was independent of childhood intellectual ability and SES, sex and social mobility. The authors concluded that both genetics and early-life adversity (low SES) contribute critically to latelife memory deficits and decline. Importantly, the availability of data on early-life intelligence helps to distinguish the relative contributions of early-life adversity and innate capabilities ${ }^{77}$. 
More recently, Danese and collaborators analysed the association between a battery of cognitive problems and childhood victimization, using prospectively collected data from two cohorts $^{76}$. The researchers concluded that victimization per se contributed relatively little to cognitive outcome, much of which was predicted by pre-trauma abilities, and by antedating factors that were considered to be confounding, including low SES.

The studies discussed so far demonstrate that an association between conventional measures of adversity and cognitive outcomes exists at the group level; however, determining the nature of the relationship and the adversity is not straightforward. Although trauma and victimization in childhood explain a minority of the variance in cognitive outcomes, genetic factors and gene-environment interactions are likely to be major contributors. Evidence of reduced cognitive performance emerges very early in childhood, and as mentioned above, is not fully explained by genetic factors and gene-environment interactions. Notably, reduced cognitive performance often precedes victimization. Together, these facts suggest that other as-yet-unconsidered aspects of early-life experience take place perinatally and in infancy and, together with genetics and gene-environment interactions, contribute critically to cognitive outcomes. This supposition led us to re-examine the construct of early-life adversity (FIG. 1).

Early-life adversity is often equated with physical and emotional stress, as assessed from the perspective of the investigator. However, early-life adversity might also be considered as any factor that disrupts the normal maturation of cognitive circuits, irrespective of the presence of conventional 'stress'. In addition to intrinsic and temporally ordered gene expression programmes, the maturation of sensory brain circuits requires patterned sensory signals from the environment, for example, sound and light patterns in the case of visual and auditory circuits, respectively (Box 1). These observations raise the possibility that aberrant patterns of signals from the environment can contribute to disrupted maturation of brain circuits, including cognitive circuits. Recent evidence has provided support for this notion. A prospective study in infants and children who had not been exposed to other conventional types of adversity demonstrated that the degree of predictability of maternally derived sensory signals correlated positively with cognitive performance at 2 years and memory at 7 years of age ${ }^{64}$. These correlations persisted when typical measures of adversity, including SES and maternal depression, were included in the models. A second study in an ethnically and demographically distinct prospective cohort identified a relationship between unpredictability of environmental signals in infancy and cognitive outcomes ${ }^{78}$.

These new studies uncover an additional dimension to the construct of early-life adversity that is distinct from its definition as 'stress', namely, chaotic unpredictable patterns of experiential signals very early in life. Examples of such patterns include inconsistent, fragmented or interrupted maternal care behaviours or chaotic households with numerous changes in providers of sensory input to the infant and child. These patterns can be measured, quantified and defined as entropy rates $63,64,79,80$. Notably, the early timing of the adversity is consistent with the Bucharest studies described above, which suggested a unique vulnerability of the developing brain to environmental and caregiver signals during the first 2 years of life $29,33,81$. This novel aspect of early-life adversity might explain a significant 
portion of the variance in cognitive outcome that is not accounted for by genetics or typical measures of adversity.

\section{Animal studies}

Animal models permit the causal relationship between adverse early-life experiences and cognitive problems to be probed. Such investigations have been conducted in non-human primates as well as rodent models. In chimpanzees, rearing by peers, a paradigm that models institutional care, resulted in impaired cognitive development ${ }^{82}$. In juvenile rhesus macaques, a similar type of early-life adversity led to complex defects in several aspects of memory, which were associated with selective reduction in corpus callosum volume on $\mathrm{MRI}^{39}$. Furthermore, impaired reversal learning was found in juvenile marmosets that were exposed to recurrent parental deprivation early in life ${ }^{40}$.

These primate studies enable causality to be established; however, to probe specific mechanisms via molecular and interventional approaches, rodent models offer the advantages of rapid development, access to tissue, low cost, genetic homogeneity and novel genetic tools. Numerous investigations, employing a spectrum of models of early-life adversity, have been conducted in rodents. Other reviews have summarized these studies in rodent models, focusing on the effects of early-life adversity on cognitive function later in life ${ }^{83-85}$, and here we describe just a few of the salient discoveries.

The effects of abusive maternal care on aspects of learning become apparent early in development, and are associated with aberrant functioning of emotional cognitive circuits involving the amygdala ${ }^{86,87}$. Several groups have reported spatial memory deficits in adult rats that were exposed to maternal deprivation in early life ${ }^{36,88,89}$, although conflicting results have been obtained ${ }^{90}$. A robust paradigm of chronic early-life adversity, consisting of simulated poverty in cages with limited nesting and bedding material, also provoked impairments in spatial and recognition memory $41,49,84,91$. These deficits were initially observed during middle age, and were associated with impaired synaptic potentiation and substantial loss of neuronal arborization and synapses ${ }^{49,91}$. The memory problems seemed to be progressive, perhaps indicating premature memory senescence, as has been suggested in humans ${ }^{49,50}$. Refinements in the cognitive tests that are employed to assess spatial memory subsequently uncovered problems in hippocampus-dependent memory by the time of adolescence in rats exposed to early-life adversity, and MRI studies revealed reduced dorsal hippocampal volume and disturbed intra-hippocampal connectivity in these animals ${ }^{92}$.

Early-life adversity in rodents, as in humans, is likely to be multifactorial ${ }^{47}$, and the mechanisms by which it leads to cognitive problems in childhood, adolescence, middle age and senescence are not fully understood. Much work has focused on potential deficits in growth factors such as $\mathrm{BDNF}^{89,93-98}$. In addition, the notion that adversity disrupts the maturation of brain circuits involved in cognition ${ }^{99-103}$ via disordered synapse strengthening and pruning ${ }^{104}$ has gained credence with the advent of novel imaging and tracing methods, as discussed in more detail below. Thus, animal models have been instrumental in furthering our understanding of the relationship between early-life adversity and cognitive function. However, these models cannot, by definition, capture the full complexity of mental illnesses 
that is seen in humans. Accordingly, we cannot claim that animals are models of specific neuropsychiatric diseases; rather, they are models for the study of disease ${ }^{105}$.

\section{Aspects of early-life adversity}

It is tempting to lump together diverse types of physical, emotional and social disadvantages, with the idea that they all converge on activating the brain's 'stress system'. This activation, in turn, 'primes' future brain programming and function, setting in motion a cascade of molecular, cellular and behavioural events that affect cognition ${ }^{10,47,106}$. However, both human and experimental data suggest that the nature of the adversity influences its effect on the developing brain. For example, the relationship between low SES and cognitive performance is most robust in developed countries and is much more variable in developing countries ${ }^{54,107}$. In addition, infants and children might be exposed to both physical and emotional aspects of adverse situations, such as displacement, war or poverty, but the emotional facets of adverse early-life experiences seem to be most salient to cognitive outcomes $28,29,56,108$.

During sensitive early-life periods, including both prenatal and postnatal epochs, environmental signals to the developing brain are filtered and conveyed by the mother ${ }^{63,109-112}$. Not surprisingly, the majority of human early-life adversity derives from abnormal types and patterns of maternal care, ranging from inconsistency and lack of sensitivity to neglect ${ }^{56,113,114}$. Total lack of maternal care has catastrophic consequences for cognitive and emotional development, as has been found in studies of institutionalized children $25,27,28,32,34,35,108,115,116$. In addition, a robust body of work has addressed the relationships between specific aspects of maternal behaviour and neurodevelopment ${ }^{63,64,113,117-123}$. Much of the work has focused on emotional outcomes, but reports have also linked aspects of maternally derived signals to the infant and child with cognitive performance ${ }^{64,124}$. The causality of such links has surfaced in experimental rodent and non-human primate experiments, in which reduction or aberrant patterns of maternal care led to memory problems during adolescence and adulthood ${ }^{92,125-130}$.

As discussed in the section on human studies above, we propose an additional dimension of the construct of early-life adversity, namely, chaotic, unpredictable patterns of experiential signals from the parent and the environment, which contribute to disrupted maturation of cognitive brain circuits. Prospective studies in infants and children who had not been exposed to other conventional types of adversity demonstrated that the degree of unpredictability of maternally derived sensory signals correlated with cognitive development at 2 years of age and memory at 7 years of age. These correlations persisted after typical measures of adversity, including SES and maternal depression, were included in the models ${ }^{64}$.

As parental signals dominate the nature of the environment of a developing infant and child, abnormal maternally derived signals are likely to constitute a type of early-life adversity. A mother's behaviour will be influenced by her environment, and she might convey this general environmental adversity to the developing brain of her child. In support of this notion, modification ofthe environment to generate simulated poverty in rodents directly 
provoked fragmented and unpredictable patterns of maternal care $37,85,126,131-133$. It is becoming clear that these patterns of maternal signals to infants are a key measure of adversity and influence cognitive outcomes, as indicated by both rodent and human studies ${ }^{63,64,84,91}$.

\section{Potential mechanisms}

Historically, brain maturation in general was considered to be protected or immune from the effects of early-life adversity and stress (Box 2). However, current thinking suggests that early-life adversity directly modulates brain development, in part via the programming actions of stress hormones that act as transcription factors, such as cortisol and its receptors ${ }^{134}$.

Complex cognitive and emotional behaviours arise from the coordinated functions of brain circuits ${ }^{135,136}$. During development, the establishment and maturation of brain circuits is modulated by salient sensory signals during sensitive or critical periods ${ }^{137-139}$ (Box 1). This process involves formation of synapses guided by molecular cues, followed by selective strengthening or pruning of synapses depending on neuronal activity: in general terms, active synapses become strengthened and inactive synapses are pruned. The signals that promote synapse loss or strengthening in sensory circuits are known, and they include light and sound patterns in visual and auditory circuits, respectively. By contrast, the specific signals that contribute to the maturation of circuits underlying functions such as memory and stress responses, and the mechanisms through which disturbances in these signals disrupt brain circuit maturation, are yet to be determined. Sensory signals emanating from the parents might promote strengthening or pruning of synapses in these circuits ${ }^{11,140,141}$. Thus, erratic, unpredictable signals could lead to enduring aberrant maturation of these circuits via deranged strengthening and pruning of synapses ${ }^{91,142}$.

The circuitry involved in memory performance is centred on the hippocampus ${ }^{143-145}$. The hippocampal formation undergoes dramatic growth and maturation during early postnatal life in both humans and rodents ${ }^{146-149}$. Several groups found excessive loss of dendrites, dendritic spines and synapses from the hippocampus in rodents that were exposed to earlylife adversity $36,49,92,150$. Similarly, reduced hippocampal volume has been found in nonhuman primates ${ }^{151,152}$ and human adolescents and adults after exposure to early-life trauma ${ }^{100,108}$. Many of the available studies are retrospective, which introduces potential caveats. However, as discussed in the next section, prospective studies have affirmed a relationship between early-life adversity and neuroimaging measures of brain circuit development.

\section{Crucial and novel study tools}

Visualization of changes in the volume and connectivity of memory-related circuits in adolescent, adult and ageing individuals provides a powerful tool for advancing our understanding of the role of early-life adversity in neurocognitive illnesses. Visible changes could help delineate potential mechanisms; for example, $\sim 40 \%$ of the cortical volume is composed of dendrites ${ }^{153,154}$, and volume loss might imply loss or poor development of 
neuronal compartments involved in connectivity, including dendritic branches and spines. In addition, a non-invasive means to visualize brain circuit structure is extremely helpful in delineating trajectories within individuals $100,101,103$, and for clarifying potential bases for sex differences in the outcomes of early-life adversity ${ }^{155-157}$. FIGURE 2 demonstrates the sex-specific differences in connectivities in brain circuits; furthermore, it shows that the rates of maturation of these circuits differ between boys and girls. Thus, adversity at a given age is likely to affect boys and girls differentially. An important question is whether the consequences of neonatal adversity on memory-related circuits are static or even reversible with time, or whether the processes set in motion by early-life adversity are progressive and/or interact with ageing processes during middle age and senescence ${ }^{158}$.

An additional impetus to optimizing imaging methods for the study of adversity-related neurological sequelae is the ability of these methods to bridge across species. Identical or analogous imaging approaches can be used in humans and in primate or rodent models, thereby aiding the identification of common bases for the relationships between early-life adversity and cognitive outcomes. The causal and mechanistic nature of adversity-provoked brain structure changes can then be probed in animal models, enabling inferences to be made about similar mechanisms in humans. Non-invasive imaging should also allow longitudinal assessment of the efficacy of any pharmacological or behavioural and lifestyle interventions.

Major innovations in imaging technology and the related analyses, including data-driven and powerful computational approaches, have advanced the study of adversity-related cognitive — in particular, memory — problems ${ }^{136,159,160}$. Volumetric analyses of the human hippocampus and hippocampal formation were initially performed retrospectively, and some of these studies identified volume reductions in adolescent, adult and ageing individuals who had experienced early-life adversity ${ }^{161-163}$. However, retrospective studies in specific populations are susceptible to confounding ${ }^{100,164}$, and later studies failed to replicate these findings 165,166 . More recently, prospective approaches have aimed to clarify the relationship between early-life adversity and imaging measures of brain circuit development ${ }^{110,167}$. These studies have provided confirmation that reduced volumes of cortical regions and the hippocampus are associated with adversity ${ }^{110,168-170}$, consistent with poor development or loss of neuronal dendritic arborization ${ }^{171}$. These findings suggest an effect of early-life adversity, in addition to the major influence of genetic factors, in governing cortical and hippocampal volumes and their response to early-life trauma ${ }^{152,172}$.

Structural connectivity in the brain has also been probed through the use of diffusion tensor imaging (DTI) and its variants ${ }^{173,174}$. Alterations in connections among brain regions that are fundamental to memory processing have been described in neurological disorders involving memory loss and dementia ${ }^{175-180}$. Prospective analyses have identified reduced efficiency of network organization in girls who have experienced substantial early-life poverty ${ }^{167}$, suggesting sex-specific vulnerabilities ${ }^{155-157,181}$. Classic DTI approaches have focused largely on delineating white matter connections (tracts) between the hippocampus and other brain regions, but high-resolution intrahippocampal DTI has also been employed. In humans, this approach, which is exemplified by the work of Yassa et al., enabled assignment of specific memory functions to discrete elements within the hippocampal formation $^{182}$. In addition, Leal and Yassa documented the effects of ageing and dementia on 
structural connectivity ${ }^{183}$. In rodent models, intra-hippocampal DTI has capitalized on the ordered arrangement of apical dendrites of hippocampal neurons, especially in the CA1 region, which is essential for processing of spatial memory 92 . Very-high-resolution, highmagnetic field scanners have uncovered disorganization and loss of these dendrites (and probably their synapses) after early-life adversity ${ }^{92}$. Interestingly these major connectivity changes were accompanied by relatively modest volume losses, demonstrating the power of using connectivity and network organization to assess the structural basis of the profound memory problems provoked by early-life adversity, at least in experimental animal models $^{171}$.

Connectomics, the study of structural and functional neuronal networks and circuits, has revolutionized the approach to understanding neurological diseases. Rather than affecting a single neuron, sets of neurons or defined regions, early-life adversity is now believed to affect brain circuits and nodes and the properties that emerge from their interactions $57,136,167,184$.

The application of these methods across species holds promise for establishing analogies between the outcomes of controlled early-life adversity in experimental models and suspected or presumed causal early-life experiences in humans. In mice, the circuitry can also be probed using a variety of viral tracing and circuit manipulation techniques ${ }^{185}$. Both anatomically and molecularly defined brain connections can be examined, and the effects of adversity on axonal and synaptic connections, including their strength, can be addressed. Chemogenetic ${ }^{186}$ or optogenetic ${ }^{187}$ activation or blocking of these brain connections could potentially be used to measure the effects of early-life adversity on the function of specific brain circuits, although these techniques have not yet been formally applied to the study of early-life adversity-induced changes in memory function.

\section{Epigenetics and methylomic biomarkers}

How might the effects of adversity that is limited to a relatively short developmental epoch endure and perhaps even progress throughout life? Conceptual and technological advances in epigenomics and related fields of study are helping us to answer this crucial, clinically relevant question.

The behaviour of individual neurons is controlled by the expression of specific genes in exquisitely orchestrated sequences that govern molecular expression, transport, interactions and degradation to drive the complex machinery of cellular communication. These coordinated gene expression programmes are governed by epigenetic effects on the chromatin - a complex consisting of DNA, histones and multiple interacting proteins $^{188,189}$. Epigenetic mechanisms, which include DNA methylation, histone modification, non-coding RNAs and the emerging concept of RNA methylation, have been reviewed extensively elsewhere ${ }^{190-192}$. Here, we present evidence that early-life adversity leads to 're-programming' of neuronal function via epigenetically mediated alterations of gene expression ${ }^{109,193,194}$. We focus on hippocampal and prefrontal cortex neurons, which are central to memory and executive functions. 
In humans, the vast maj ority ofstudies that have directly addressed alterations in gene expression have employed post-mortem tissue, although some have employed tissue blocks resected from individuals undergoing surgery for epilepsy ${ }^{195}$, and most studies on the effects of early-life adversity have focused on psychiatric problems ${ }^{196,197}$. In experimental models, including primates ${ }^{198,199}$, a wide and growing literature is documenting major adversityinduced epigenomic changes in the hippocampus and prefrontal cortex through the use of sophisticated methodologies, including RNA sequencing, ribosome tagging (RiboTag) and chromatin immuno-precipitation sequencing (ChlP-Seq). Data-driven analyses and bioinformatics $^{200-202}$ are used to identify important gene sets and molecular pathways that might contribute to neuronal deficits ${ }^{203,204}$, as well as transcriptional master regulators that potentially drive large-scale changes in gene expression ${ }^{7,205-208}$. Stressful early-life experiences are thought to programme neurons via the glucocorticoid receptor, which functions as a transcription factor ${ }^{209}$. Additional key transcriptional master regulators are being discovered, including the homeobox protein OTX2 $\left(\mathrm{REF}^{206}\right)$ and RE1-silencing transcription factor ${ }^{207,208}$. Several studies have employed hypothesis-driven approaches centred on the effects of early-life adversity on the expression of single genes or gene sets, especially those involved in synaptic growth and neuronal connectivity ${ }^{91,210-215}$. Studies in animal models have identified numerous pathways that contribute to neuronal deficits, which might underlie memory problems. However, more work is needed to translate these findings to the clinical prevention of adversity-provoked cognitive deficits in humans.

To enable therapeutic intervention, individuals at risk of adversity-related cognitive problems will need to be identified as early as possible. The imaging approaches described above hold promise for identifying predictive biomarkers for the risk of cognitive or affective disorders, but an additional avenue involves the study of epigenetic markers in peripheral cells, and specifically of DNA methylation profiles (methylomics). DNA methylation profiles change with age $\mathrm{e}^{216-218}$ and have been suggested to represent a biological ageing clock ${ }^{219}$. Although the relationship between the methylation profiles in buccal swab-derived cells or peripheral white blood cells and those in cortical and hippocampal neurons is limited ${ }^{220,221}$, acceleration of the 'methylation age' of DNA in white blood cells might portend neurological disorders, especially cognitive decline and dementia ${ }^{219,222-225}$. A growing number ofstudies are comparing DNA methylation signatures in individuals exposed to early-life adversity with signatures in individuals with apparently optimal infancy and childhood ${ }^{226}$. These studies include paediatric, adult and ageing cohorts ${ }^{227-229}$. Only a few studies have found associations between methyl- ation signatures and reductions in cognitive abilities ${ }^{227}$. The difficulty in identifying predictive biomarkers for cognitive defects and dementia in these cross-sectional studies derives from the considerable variance among individuals. Longitudinal and within-individual comparisons are now emerging 230,231 . These comparisons hold promise for uncovering methylation patterns that might be predictive markers for the risk of cognitive problems or dementia later in life.

\section{Potential interventions}

Adverse life experiences affect nearly $50 \%$ of children in the USA ${ }^{232}$. Policy changes driven by observational ${ }^{233}$ and interventional ${ }^{234}$ studies aim to mitigate childhood poverty, yet our 
ability to prevent other types of early adversity is limited. Therefore, efforts to mitigate adversity-related neurological disorders, including memory decline and dementia, should probably focus on post hoc interventions. Key questions that are central to any intervention relate to its timing: what is the duration of the sensitive developmental period when adversity most profoundly affects cognition, and how late can we reverse the resulting deficits?

No definitive answers to either question have yet been obtained, but important data are emerging. Human memory circuits have been shown evolve during infancy and childhood $^{235-237}$, and the pioneering studies of Romanian infants and children raised in orphanages suggest that the first 2 years of life are a particularly sensitive period to the effects of adversity ${ }^{29}$, although evidence exists for cumulative effects of adversity on cognitive function throughout childhood ${ }^{13,238,239}$. In experimental animals, critical periods for the normal development of memory circuits and functions have been identified ${ }^{240,241}$, and studies in animal models have advanced our understanding of the mechanisms that contribute to these critical periods. Although developmental stages of the human and rodent brain do not correlate precisely, comparative development of the memory-subserving hippocampal formation across species has been assessed ${ }^{242}$.

As regards the time frame during which interventions might be effective, studies in orphans suggested that cognitive recovery is lower in individuals who were provided with adoptive families later than 24 months of age than in infants who were adopted earlier ${ }^{25,29}$. Similarly, in experimental models, early interventions using pharmacological and epigenetic approaches enabled restoration of memory in adversity-experiencing rats ${ }^{91,122}$, whereas later interventions were less effective ${ }^{243}$. Together, these findings suggest that lengthening the sensitive period when neuronal and circuit plasticity enables intervention would be a major advance in post hoc interventions after early-life adversity.

The mechanisms that govern the sensitive window for memory-related circuits are unknown; however, major insights have been gained from the study of sensitive periods in the auditory circuitry. During development of the rodent auditory system, there is a critical period during which patterned sensory auditory inputs govern the maturation of the thalamocortical auditory circuit ${ }^{244}$. Aberrant neuronal activity, such as seizures, during this period disrupts circuit maturation $^{245}$. Recently, elegant work has identified the neurobiological basis of the critical period, enabling its extension to a later age ${ }^{246}$. The principles of critical periods have now been demonstrated for several sensory brain circuits ${ }^{246,247}$, and evidence for critical periods in the development of the hippocampus-centred memory circuitry has been uncovered $49,242,248,249$. In analogy to the auditory system, aberrant neuronal firing (seizures) $)^{207}$ and fragmented or unpredictable sensory input ${ }^{11,37}$ disrupt the maturation of circuits underlying memory and emotions. Taken together, these observations suggest that extension or reopening of the critical period for memory circuitry could enable reversal or prevention of memory defects resulting from early-life adversity.

Interventions that might be helpful both during development and in the adult and ageing brain include a variety of growth factors including BDNF, as well as exercise ${ }^{250}$. Physical 
activity has been shown to improve memory in rodent models of ageing and dementia ${ }^{251,252}$, and is associated with better cognitive function in ageing humans ${ }^{253-256}$.

\section{Conclusions and future directions}

The correlation between early-life adversity and neurological health and disease is supported by strong epidemiological evidence. The nature of this correlation is complex: although genetic factors clearly modulate the consequences of the adversity on neurological outcomes, a distinct influence of adversity across diverse genotypes is apparent, suggesting that this environmental factor has an important role in shaping cognition.

Robust evidence from animal models and prospective studies in specific human populations indicate that aspects of early-life adversity influence cognitive brain development and function. Exposure to adversity during the first few years of life has the most profound and enduring effects on outcomes, consistent with a sensitive developmental period.

Notably, our notions of the nature of early-life adversity are in flux. Beyond poverty, abuse and neglect, unpredictable and chaotic parental and environmental signals to the developing infant are emerging as important contributors to early-life adversity. These factors do not necessarily coexist with other types of adversity, and could help to explain a substantial portion of the variance in cognitive outcomes during childhood.

The mechanisms through which early-life adversity influences the brain are numerous, and might include modulation of stress-related processes. Novel technologies, in particular epigenomic techniques and neuroimaging, are increasing our understanding of the effects of early-life adversity on brain circuit maturation, on gene expression profiles and on the function of individual neurons and neuronal ensembles that are pivotal to cognitive and other complex behaviours.

Numerous questions remain unresolved and should be topics for future studies. For example, as components of the cognitive circuitry mature at different ages, do distinct sensitive ages of exposure exist for different types of outcomes (for example, executive function versus memory)? Also, what are the fundamental sex-dependent differences in cognitive circuits and their development (FIG. 2), and how does sex influence vulnerability to and expression of cognitive problems that follow early-life adversity? Finally, if fragmented, unpredictable environmental and parental signals early in life can contribute to cognitive problems, does parental cell phone use, which can disrupt patterns of sensory signals to the infant, constitute a novel form of adversity ${ }^{257}$ ?

The effects of early-life adversity on cognitive outcomes have occupied human thinking for millennia, and this issue remains as topical and vexing as ever as we enter the third decade of the 21 st century.

\section{Acknowledgements}

The authors' work has been supported by NIH grants NS28912, NS35439, NS108296, MH73136 and MH096889, and by the Hewitt Foundation for Biomedical Research. 


\section{References}

1. Prince M et al. World Alzheimer Report 2015. The global impact of dementia: an analysis of prevalence, incidence, cost and trends. Alzheimer's Disease International https://www.alz.co.uk/ research/world-report-2015 (2015).

2. Prince M, Guerchet M \& Prina M Policy Brief: the global impact of dementia 2013-2050. Alzheimer's Disease International https://www.alz.co.uk/research/G8-policy-brief (2013).

3. Stern Y et al. Whitepaper: defining and investigating cognitive reserve, brain reserve, and brain maintenance. Alzheimers Dement. 10.1016/j.jalz.2018.07.219 (2018).

4. Revelas $\mathrm{M}$ et al. Review and meta- analysis of genetic polymorphisms associated with exceptional human longevity. Mech. Ageing Dev 175, 24-34 (2018). [PubMed: 29890178]

5. Freudenberg- Hua Y, Li W \& Davies $P$ The role of genetics in advancing precision medicine for Alzheimer's disease - a narrative review. Front. Med 5, 108 (2018).

6. Caspi A et al. Influence of life stress on depression: moderation by a polymorphism in the 5-HTT gene. Science. 301, 386-389 (2003). [PubMed: 12869766]

7. Klengel T \& Binder EB Epigenetics of stress- related psychiatric disorders and genexenvironment interactions. Neuron 86, 1343-1357 (2015). [PubMed: 26087162]

8. Brown AS, Susser ES, Lin SP, Neugebauer R \& Gorman JM Increased risk of affective disorders in males after second trimester prenatal exposure to the Dutch hunger winter of 1944-45. Br. J. Psychiatry 166, 601-606 (1995). [PubMed: 7620744]

9. Eriksson M, Räikkönen K \& Eriksson JG Early life stress and later health outcomes-findings from the Helsinki Birth Cohort Study. Am. J. Hum. Biol 26, 111-116 (2014). [PubMed: 24375506]

10. Lupien SJ, McEwen BS, Gunnar MR \& Heim C Effects of stress throughout the lifespan on the brain, behaviour and cognition. Nat. Rev. Neurosci 10, 434-445 (2009). [PubMed: 19401723]

11. Chen Y \& Baram TZ Toward understanding how early- life stress reprograms cognitive and emotional brain networks. Neuropsychopharmacology 41, 197-206 (2016). [PubMed: 26105143]

12. Novick AM et al. The effects of early life stress on reward processing. J. Psychiatr. Res 101, 80103 (2018). [PubMed: 29567510]

13. Raymond C, Marin M-F, Majeur D \& Lupien S Early child adversity and psychopathology in adulthood: HPA axis and cognitive dysregulations as potential mechanisms. Prog. Neuropsychopharmacol. Biol. Psychiatry 85, 152-160 (2018). [PubMed: 28751271]

14. Millan MJ et al. Cognitive dysfunction in psychiatric disorders: characteristics, causes and the quest for improved therapy. Nat. Rev. Drug Discov 11, 141-168 (2012). [PubMed: 22293568]

15. Osler M, Avlund K \& Mortensen EL Socioeconomic position early in life, cognitive development and cognitive change from young adulthood to middle age. Eur. J. Public Health 23, 974-980 (2013). [PubMed: 23093718]

16. Sheridan MA \& McLaughlin KA Dimensions of early experience and neural development: deprivation and threat. Trends Cogn. Sci 18, 580-585 (2014). [PubMed: 25305194]

17. Kaplan GA et al. Childhood socioeconomic position and cognitive function in adulthood. Int. J. Epidemiol 30, 256-263 (2001). [PubMed: 11369724]

18. Melrose RJ et al. Early life development in a multiethnic sample and the relation to late life cognition. J. Gerontol. B Psychol. Sci. Soc. Sci 70, 519-531 (2015). [PubMed: 24389122]

19. Marden JR, Tchetgen Tchetgen EJ, Kawachi I \& Glymour MM Contribution of socioeconomic status at 3 life-course periods to late- life memory function and decline: early and late predictors of dementia risk. Am. J. Epidemiol 186, 805-814 (2017). [PubMed: 28541410]

20. Elbejjani $\mathrm{M}$ et al. Life- course socioeconomic position and hippocampal atrophy in a prospective cohort of older adults. Psychosom. Med 79, 14-23 (2017). [PubMed: 27428856]

21. Staff RT, Hogan MJ \& Whalley LJ The influence of childhood intelligence, social class, education and social mobility on memory and memory decline in late life. Age Ageing 47, 847-852 (2018). [PubMed: 30084877]

22. Mosing MA, Lundholm C, Cnattingius S, Gatz M \& Pedersen NL Associations between birth characteristics and age- related cognitive impairment and dementia: a registry- based cohort study. PLOS Med. 15, e1002609 (2018). [PubMed: 30020924] 
23. Fors S, Lennartsson C \& Lundberg O Childhood living conditions, socioeconomic position in adulthood, and cognition in later life: exploring the associations. J. Gerontol. B Psychol. Sci. Soc. Sci 64B, 750-757

24. Everson- Rose SA, Mendes De Leon CF Bienias JL Wilson RS \& Evans DA Early life conditions and cognitive functioning in later life. Am. J. Epidemiol 158, 1083-1089 (2003) [PubMed: 14630604]

25. Pollak SDet al Neurodevelopmental effects of early deprivation in postinstitutionalized children. Child Dev. 81, 224-236 (2010) [PubMed: 20331664]

26. Cohen NJ, Lojkasek M, Zadeh ZY, Pugliese M \& Kiefer H Children adopted from China: a prospective study of their growth and development. J. Child Psychol. Psychiatry 49, 458-468 (2008). [PubMed: 18221351]

27. Johnson DE et al. Growth and associations between auxology, caregiving environment, and cognition in socially deprived Romanian children randomized to foster vs ongoing institutional care. Arch. Pediatr. Adolesc. Med 164, 507-516 (2010). [PubMed: 20368481]

28. Loman MM, Wiik KL, Frenn KA, Pollak SD \& Gunnar MR Postinstitutionalized children's development: growth, cognitive, and language outcomes. J. Dev. Behav. Pediatr 30, 426-434 (2009). [PubMed: 19692931]

29. Nelson CA et al. Cognitive recovery in socially deprived young children: the Bucharest Early Intervention Project. Science 318, 1937-1940 (2007). [PubMed: 18096809]

30. van den Dries L, Juffer F, van Ijzendoorn MH \& Bakermans- Kranenburg MJ Infants' physical and cognitive development after international adoption from foster care or institutions in China. J. Dev. Behav. Pediatr 31, 144-150 (2010). [PubMed: 20110827]

31. Pechtel P \& Pizzagalli DA Effects of early life stress on cognitive and affective function: an integrated review of human literature. Psychopharmacology 214, 55-70 (2011). [PubMed: 20865251]

32. Loman MM et al. The effect of early deprivation on executive attention in middle childhood. J. Child Psychol. Psychiatry 54, 37-45 (2013). [PubMed: 22924462]

33. McDermott JM, Westerlund A, Zeanah CH, Nelson CA \& Fox NA Early adversity and neural correlates of executive function: implications for academic adjustment. Dev. Cogn. Neurosci 2, S59-S66 (2012). [PubMed: 22682911]

34. Wiik KL et al. Behavioral and emotional symptoms of post- institutionalized children in middle childhood. J. Child Psychol. Psychiatry 52, 56-63 (2011). [PubMed: 20649913]

35. Lawler J \& Gunnar MR in Handbook of Early Child Education (ed. Pianta RC) 457-479 (Guilford Press, 2012).

36. Huot RL, Plotsky PM, Lenox RH \& McNamara RK Neonatal maternal separation reduces hippocampal mossy fiber density in adult Long Evans rats. Brain Res. 950, 52-63 (2002). [PubMed: 12231228]

37. Molet $\mathrm{J}$ et al. Fragmentation and high entropy of neonatal experience predict adolescent emotional outcome. Transl Psychiatry 6, e702 (2016). [PubMed: 26731439]

38. Kohl C et al. Hippocampal neuroligin-2 links early- life stress with impaired social recognition and increased aggression in adult mice. Psychoneuroendocrinology 55, 128-143 (2015). [PubMed: 25765754]

39. Sánchez MM, Hearn EF, Do D, Rilling JK \& Herndon JG Differential rearing affects corpus callosum size and cognitive function of rhesus monkeys. Brain Res. 812, 38-49 (1998). [PubMed: 9813233]

40. Pryce CR, Dettling A, Spengler M, Spaete C \& Feldon J Evidence for altered monoamine activity and emotional and cognitive disturbance in marmoset monkeys exposed to early life stress. Ann. NY Acad. Sci 1032, 245-249 (2004). [PubMed: 15677420]

41. Bath KG et al. Early life stress leads to developmental and sex selective effects on performance in a novel object placement task. Neurobiol. Stress 7, 57-67 (2017). [PubMed: 28462362]

42. Roozendaal B, Brunson KL, Holloway BL, McGaugh JL \& Baram TZ Involvement of stressreleased corticotropin- releasing hormone in the basolateral amygdala in regulating memory consolidation. Proc. Natl Acad. Sci. USA 99, 13908-13913 (2002). [PubMed: 12361983] 
43. Kosten TA et al. Memory impairments and hippocampal modifications in adult rats with neonatal isolation stress experience. Neurobiol. Learn. Mem 88, 167-176 (2007). [PubMed: 17543553]

44. Guijarro JZ et al. Effects of brief and long maternal separations on the HPA axis activity and the performance of rats on context and tone fear conditioning. Behav. Brain Res 184, 101-108 (2007). [PubMed: 17697719]

45. Raineki $\mathrm{C}$ et al. Functional emergence of the hippocampus in context fear learning in infant rats. Hippocampus 20, 1037-1046 (2010). [PubMed: 19739248]

46. Hulshof HJ et al. Maternal separation decreases adult hippocampal cell proliferation and impairs cognitive performance but has little effect on stress sensitivity and anxiety in adult Wistar rats. Behav. Brain Res 216, 552-560 (2011). [PubMed: 20816703]

47. Lucassen PJ et al. Perinatal programming of adult hippocampal structure and function; emerging roles of stress, nutrition and epigenetics. Trends Neurosci. 36, 621-631 (2013). [PubMed: 23998452]

48. Naninck EF et al. Chronic early life stress alters developmental and adult neurogenesis and impairs cognitive function in mice. Hippocampus 25, 309-328 (2015). [PubMed: 25269685]

49. Brunson KL et al. Mechanisms of late-onset cognitive decline after early- life stress. J. Neurosci 25, 9328-9338 (2005). [PubMed: 16221841]

50. Maras PM \& Baram TZ Sculpting the hippocampus from within: stress, spines, and CRH. Trends Neurosci. 35, 315-324 (2012). [PubMed: 22386641]

51. Franke K, Gaser C, Roseboom TJ, Schwab M \& de Rooij SR Premature brain aging in humans exposed to maternal nutrient restriction during early gestation. Neuroimage 173, 460-471 (2018). [PubMed: 29074280]

52. de Groot RH et al. Prenatal famine exposure and cognition at age 59 years. Int. J. Epidemiol 40, 327-337 (2011). [PubMed: 21247885]

53. He $\mathrm{P}$ et al. Prenatal malnutrition and adult cognitive impairment: a natural experiment from the 1959-1961 Chinese famine. Br. J. Nutr 120, 198-203 (2018). [PubMed: 29720288]

54. Crookston BT, Forste R, McClellan C, Georgiadis A \& Heaton TB Factors associated with cognitive achievement in late childhood and adolescence: the young lives cohort study of children in Ethiopia, India, Peru, and Vietnam. BMC Pediatr. 14, 253 (2014). [PubMed: 25282338]

55. Tottenham $\mathrm{N}$ et al. Prolonged institutional rearing is associated with atypically large amygdala volume and difficulties in emotion regulation. Dev. Sci 13, 46-61 (2010). [PubMed: 20121862]

56. Nelson CA, Bos K, Gunnar MR \& Sonuga- Barke EJSV The neurobiological toll of early human deprivation. Monogr. Soc. Res. Child Dev 76, 127-146 (2011). [PubMed: 25018565]

57. Callaghan BL \& Tottenham N The neuroenvironmental loop of plasticity: a cross- species analysis of parental effects on emotion circuitry development following typical and adverse caregiving. Neuropsychopharmacology 41, 163-176 (2016). [PubMed: 26194419]

58. Duncan GJ, Yeung WJ, Brooks- Gunn J \& Smith JR How much does childhood poverty affect the life chances of children? Am. Sociol. Rev 63, 406-423 (1998).

59. Hackman DA \& Farah MJ Socioeconomic status and the developing brain. Trends Cogn. Sci 13, 65-73 (2009). [PubMed: 19135405]

60. Volkow ND et al. The conception of the ABCD study: from substance use to a broad NIH collaboration. Dev. Cogn. Neurosci 32, 4-7 (2018). [PubMed: 29051027]

61. Karlsson L et al. Cohort profile: the Finnbrain Birth Cohort Study (FinnBrain). Int. J. Epidemiol 47, 15-16j (2018). [PubMed: 29025073]

62. Hermus MAA et al. Differences in optimality index between planned place of birth in a birth centre and alternative planned places of birth, a nationwide prospective cohort study in The Netherlands: results of the Dutch Birth Centre Study. BMJ Open 7, e016958 (2017).

63. Glynn LM et al. Prenatal maternal mood patterns predict child temperament and adolescent mental health. J. Affect. Disord 228, 83-90 (2018). [PubMed: 29241049]

64. Davis EP et al. Exposure to unpredictable maternal sensory signals influences cognitive development across species. Proc. Natl Acad. Sci. USA 114, 10390-10395 (2017). [PubMed: 28893979] 
65. Zannas AS et al. Lifetime stress accelerates epigenetic aging in an urban, African American cohort: relevance of glucocorticoid signaling. Genome Biol. 16, 266 (2015). [PubMed: 26673150]

66. Wilson RS et al. Socioeconomic characteristics of the community in childhood and cognition in old age. Exp. Aging Res 31, 393-407 (2005). [PubMed: 16147459]

67. González HM, Tarraf W, Bowen ME, Johnson- Jennings MD \& Fisher GG What do parents have to do with my cognitive reserve? Life course perspectives on twelve- year cognitive decline. Neuroepidemiology 41, 101-109 (2013). [PubMed: 23860477]

68. Sha T, Yan Y \& Cheng W Associations of childhood socioeconomic status with mid- life and latelife cognition in Chinese middle- aged and older population based on a 5-year period cohort study. Int. J. Geriatr. Psychiatry 33, 1335-1345 (2018). [PubMed: 29971839]

69. Luo Y \& Waite LJ The impact of childhood and adult SES on physical, mental, and cognitive wellbeing in later life. J. Gerontol. B Psychol. Sci. Soc. Sci 60, S93-S101 (2005). [PubMed: 15746030]

70. Turrell $\mathrm{G}$ et al. Socioeconomic position across the lifecourse and cognitive function in late middle age. J. Gerontol. B Psychol. Sci. Soc. Sci 57, S43-S51 (2002). [PubMed: 11773232]

71. Zhang Z, Gu D \& Hayward MD Early life influences on cognitive impairment among oldest old chinese. J. Gerontol. B Psychol. Sci. Soc. Sci 63, S25-S33 (2008). [PubMed: 18332198]

72. Chen Z-Y et al. Genetic variant BDNF (Val66Met) polymorphism alters anxiety- related behavior. Science 314, 140-143 (2006). [PubMed: 17023662]

73. Chen Z-Y, Bath K, McEwen B, Hempstead B \& Lee F Impact of genetic variant BDNF (Val66Met) on brain structure and function. Novartis Found. Symp 2008, 180-188 (2008).

74. Labermaier $\mathrm{C}$ et al. A polymorphism in the Crhr1 gene determines stress vulnerability in male mice. Endocrinology 155, 2500-2510 (2014). [PubMed: 24773341]

75. Dedic $\mathrm{N}$ et al. Cross- disorder risk gene CACNA1C differentially modulates susceptibility to psychiatric disorders during development and adulthood. Mol. Psychiatry 23, 533-543 (2018). [PubMed: 28696432]

76. Danese A et al. The origins of cognitive deficits in victimized children: implications for neuroscientists and clinicians. Am. J. Psychiatry 174, 349-361 (2017). [PubMed: 27794691]

77. Whalley LJ et al. How the 1932 and 1947 mental surveys of Aberdeen schoolchildren provide a framework to explore the childhood origins of late onset disease and disability. Maturitas 69, 365372 (2011). [PubMed: 21700406]

78. Davis EP et al. Across continents and demographics, unpredictable maternal signals impact children's neurodevelopment. EBioMedicine 10.1016/j.ebiom.2019.07.025 (2019).

79. Vegetabile BG, Stout- Oswald SA, Poggi Davis E, Baram TZ \& Stern HS Estimating the entropy rate of finite Markov chains with application to behavior studies. J. Educ. Behav. Stat 44, 282-308 (2019).

80. Center Conte. Measuring unpredictable maternal sensory signals. UCI https://contecenter.uci.edu/ measuring-unpredictable-maternal-sensory-signals/ (2019).

81. Nelson ED \& Monteggia LM Epigenetics in the mature mammalian brain: effects on behavior and synaptic transmission. Neurobiol. Learn. Mem 96, 53-60 (2011). [PubMed: 21396474]

82. van Ijzendoorn MH, Bard KA, Bakermans-Kranenburg MJ \& Ivan K Enhancement of attachment and cognitive development of young nursery- reared chimpanzees in responsive versus standard care. Dev. Psychobiol 51, 173-185 (2009). [PubMed: 19016474]

83. van Bodegom M, Homberg JR \& Henckens MJAG Modulation of the hypothalamic-pituitaryadrenal axis by early life stress exposure. Front. Cell. Neurosci 11, 87 (2017). [PubMed: 28469557]

84. Molet J, Maras PM, Avishai- Eliner S \& Baram TZ Naturalistic rodent models of chronic earlylife stress. Dev. Psychobiol 56, 1675-1688 (2014). [PubMed: 24910169]

85. Walker C-DD et al. Chronic early life stress induced by limited bedding and nesting (LBN) material in rodents: critical considerations of methodology, outcomes and translational potential. Stress 20, 421-448 (2017). [PubMed: 28617197]

86. Raineki C, Cortés MR, Belnoue L \& Sullivan RM Effects of early- life abuse differ across development: infant social behavior deficits are followed by adolescent depressive- like behaviors mediated by the amygdala. J. Neurosci 32, 7758-7765 (2012). [PubMed: 22649253] 
87. Sevelinges Y, Sullivan RM, Messaoudi B \& Mouly A-M Neonatal odor- shock conditioning alters the neural network involved in odor fear learning at adulthood. Learn. Mem 15, 649-656 (2008). [PubMed: 18772252]

88. Oomen CA et al. Severe early life stress hampers spatial learning and neurogenesis, but improves hippocampal synaptic plasticity and emotional learning under high- stress conditions in adulthood. J. Neurosci 30, 6635-6645 (2010). [PubMed: 20463226]

89. Schaaf MJ et al. Correlation between hippocampal BDNF mRNA expression and memory performance in senescent rats. Brain Res. 915, 227-233 (2001). [PubMed: 11595212]

90. Loi $\mathrm{M}$ et al. Effects of early- life stress on cognitive function and hippocampal structure in female rodents. Neuroscience 342, 101-119 (2017). [PubMed: 26297897]

91. Ivy AS et al. Hippocampal dysfunction and cognitive impairments provoked by chronic early- life stress involve excessive activation of CRH receptors. J. Neurosci 30, 13005-13015 (2010). [PubMed: 20881118]

92. Molet $\mathbf{J}$ et al. MRI uncovers disrupted hippocampal microstructure that underlies memory impairments after early- life adversity. Hippocampus 26, 1618-1632 (2016). [PubMed: 27657911]

93. Wearick- Silva LE et al. Running during adolescence rescues a maternal separation- induced memory impairment in female mice: potential role of differential exon- specific BDNF expression. Dev. Psychobiol 59, 268-274 (2017). [PubMed: 27807856]

94. Arcego DM et al. Early life adversities or high fat diet intake reduce cognitive function and alter BDNF signaling in adult rats: interplay of these factors changes these effects. Int. J. Dev. Neurosci 50, 16-25 (2016). [PubMed: 26948152]

95. de Lima MNM et al. Early life stress decreases hippocampal BDNF content and exacerbates recognition memory deficits induced by repeated D-amphetamine exposure. Behav. Brain Res 224, 100-106 (2011). [PubMed: 21645554]

96. Gatt JM et al. Interactions between BDNF Val66Met polymorphism and early life stress predict brain and arousal pathways to syndromal depression and anxiety. Mol. Psychiatry 14, 681-695 (2009). [PubMed: 19153574]

97. Grassi- Oliveira R, Stein LM, Lopes RP, Teixeira AL \& Bauer ME Low plasma brain- derived neurotrophic factor and childhood physical neglect are associated with verbal memory impairment in major depression-a preliminary report. Biol. Psychiatry 64, 281-285 (2008). [PubMed: 18406398]

98. Bath KG, Schilit A \& Lee FS Stress effects on BDNF expression: effects of age, sex, and form of stress. Neuroscience 239, 149-156 (2013). [PubMed: 23402850]

99. Amso D \& Scerif $G$ The attentive brain: insights from developmental cognitive neuroscience. Nat. Rev. Neurosci 16, 606-619 (2015). [PubMed: 26383703]

100. Teicher MH, Samson JA, Anderson CM \& Ohashi K The effects of childhood maltreatment on brain structure, function and connectivity. Nat. Rev. Neurosci 17, 652-666 (2016). [PubMed: 27640984]

101. Casey BJ, Heller AS, Gee DG \& Cohen AO Development of the emotional brain. Neurosci. Lett 693, 29-34 (2019). [PubMed: 29197573]

102. Chen Y et al. Converging, synergistic actions of multiple stress hormones mediate enduring memory impairments after acute simultaneous stresses. J. Neurosci 36, 11295-11307 (2016). [PubMed: 27807170]

103. Pattwell SS et al. Dynamic changes in neural circuitry during adolescence are associated with persistent attenuation of fear memories. Nat. Commun 7, 11475 (2016). [PubMed: 27215672]

104. Schafer DP et al. Microglia sculpt postnatal neural circuits in an activity and complementdependent manner. Neuron 74, 691-705 (2012). [PubMed: 22632727]

105. Gordon J Translational research: from research findings to transformative treatments. NIMH https://www.nimh.nih.gov/about/director/messages/2018/translational-research-from-researchfindingsto-transformative-treatments.shtml (2018).

106. Krugers HJ et al. Early life adversity: lasting consequences for emotional learning. Neurobiol. Stress 6, 14-21 (2017). [PubMed: 28229105]

107. Agidew AA \& Singh KN Determinants of food insecurity in the rural farm households in South Wollo Zone of Ethiopia: the case of the Teleyayen subwatershed. Agric. Food Econ 6, 10 (2018). 
108. Hodel AS et al. Duration of early adversity and structural brain development in postinstitutionalized adolescents. Neuroimage 105, 112-119 (2015). [PubMed: 25451478]

109. Bale TL et al. Early life programming and neurodevelopmental disorders. Biol. Psychiatry 68 , 314-319 (2010). [PubMed: 20674602]

110. Sandman CA et al. Cortical thinning and neuropsychiatric outcomes in children exposed to prenatal adversity: a role for placental CRH? Am. J. Psychiatry 175, 471-479 (2018). [PubMed: 29495899]

111. Sandman CA, Davis EP, Buss C \& Glynn LM Prenatal programming of human neurological function. Int. J. Pept 2011, 837596 (2011). [PubMed: 21760821]

112. Gee DG et al. Maternal buffering of human amygdala- prefrontal circuitry during childhood but not during adolescence. Psychol. Sci 25, 2067-2078 (2014). [PubMed: 25280904]

113. Bowlby J Research into the origins of delinquent behaviour. Br. Med. J 1, 570-573 (1950). [PubMed: 20787782]

114. Hostinar CE \& Gunnar MR The developmental effects of early life stress. Curr. Dir. Psychol. Sci 22, 400-406 (2013). [PubMed: 25419054]

115. Gunnar MR, Morison SJ, Chisholm K \& Schuder M Salivary cortisol levels in children adopted from Romanian orphanages. Dev. Psychopathol 13, 611-628 (2001). [PubMed: 11523851]

116. Gunnar MR Reversing the effects of early deprivation after infancy: giving children families may not be enough. Front. Neurosci 4, 170 (2010). [PubMed: 21152350]

117. Masur EF, Flynn V \& Eichorst DL Maternal responsive and directive behaviours and utterances as predictors of children's lexical development. J. Child Lang 32, 63-91 (2005). [PubMed: 15779877]

118. NICHD Early Care Research Network. Chronicity of maternal depressive symptoms, maternal sensitivity, and child functioning at 36 months. Dev. Psychol 35, 1297-1310 (1999). [PubMed: 10493655]

119. NICHD Early Care Research Network. Infant-mother attachment classification: risk and protection in relation to changing maternal caregiving quality. Dev. Psychol 42, 38-58 (2006). [PubMed: 16420117]

120. Hane AA, Henderson HA, Reeb- Sutherland BC \& Fox NA Ordinary variations in human maternal caregiving in infancy and biobehavioral development in early childhood: a follow- up study. Dev. Psychobiol 52, 558-567 (2010). [PubMed: 20806328]

121. Belsky J \& Fearon RMP Early attachment security, subsequent maternal sensitivity, and later child development: does continuity in development depend upon continuity of caregiving? Attach. Hum. Dev 4, 361-387 (2002). [PubMed: 12537851]

122. Weaver ICG et al. Epigenetic programming by maternal behavior. Nat. Neurosci 7, 847-854 (2004). [PubMed: 15220929]

123. Champagne FA, Francis DD, Mar A \& Meaney MJ Variations in maternal care in the rat as a mediating influence for the effects of environment on development. Physiol. Behav 79, 359-371 (2003). [PubMed: 12954431]

124. Coates DL \& Lewis M Early mother-infant interaction and infant cognitive status as predictors of school performance and cognitive behavior in six- yearolds. Child Dev. 55, 1219 (1984). [PubMed: 6488954]

125. Parker KJ, Buckmaster CL, Justus KR, Schatzberg AF \& Lyons DM Mild early life stress enhances prefrontal- dependent response inhibition in monkeys. Biol. Psychiatry 57, 848-855 (2005). [PubMed: 15820705]

126. Rice CJ, Sandman CA, Lenjavi MR \& Baram TZ A novel mouse model for acute and longlasting consequences of early life stress. Endocrinology 149, 4892-4900 (2008). [PubMed: 18566122]

127. Sánchez MM, Ladd CO \& Plotsky PM Early adverse experience as a developmental risk factor for later psychopathology: evidence from rodent and primate models. Dev. Psychopathol 13, 419-449 (2001). [PubMed: 11523842]

128. Spencer- Booth Y \& Hinde RA The effects of 13 days maternal separation on infant rhesus monkeys compared with those of shorter and repeated separations. Anim. Behav 19, 595-605 (1971). [PubMed: 5003219] 
129. Fenoglio KA, Brunson KL \& Baram TZ Hippocampal neuroplasticity induced by early-life stress: functional and molecular aspects. Front. Neuroendocrinol 27, 180-192 (2006). [PubMed: 16603235]

130. Meaney MJ, Aitken DH, van Berkel C, Bhatnagar S \& Sapolsky RM Effect of neonatal handling on age- related impairments associated with the hippocampus. Science 239, 766-768 (1988). [PubMed: 3340858]

131. Gilles EE, Schultz L \& Baram TZ Abnormal corticosterone regulation in an immature rat model of continuous chronic stress. Pediatr. Neurol 15, 114-119 (1996). [PubMed: 8888044]

132. Ivy AS, Brunson KL, Sandman C \& Baram TZ Dysfunctional nurturing behavior in rat dams with limited access to nesting material: a clinically relevant model for early- life stress. Neuroscience 154, 1132-1142 (2008). [PubMed: 18501521]

133. Wang X-D et al. Forebrain CRF1 modulates early- life stress- programmed cognitive deficits. J. Neurosci 31, 13625-13634 (2011). [PubMed: 21940453]

134. Herman JP \& Tasker JG Paraventricular hypothalamic mechanisms of chronic stress adaptation. Front. Endocrinol 7, 137 (2016).

135. Redish AD \& Gordon JA (eds) Computational Psychiatry: New Perspectives on Mental Illness (MIT Press, 2016).

136. Bassett DS \& Sporns O Network neuroscience. Nat. Neurosci 20, 353-364 (2017). [PubMed: 28230844]

137. Espinosa JS \& Stryker MP Development and plasticity of the primary visual cortex. Neuron 75 , 230-249 (2012). [PubMed: 22841309]

138. Khazipov R et al. Early motor activity drives spindle bursts in the developing somatosensory cortex. Nature 432, 758-761 (2004). [PubMed: 15592414]

139. Hensch TK Critical period mechanisms in developing visual cortex. Curr. Top. Dev. Biol 69, 215237 (2005). [PubMed: 16243601]

140. Korosi A et al. Early- life experience reduces excitation to stress- responsive hypothalamic neurons and reprograms the expression of corticotropinreleasing hormone. J. Neurosci 30, 703713 (2010). [PubMed: 20071535]

141. Singh- Taylor A et al. NRSF- dependent epigenetic mechanisms contribute to programming of stress- sensitive neurons by neonatal experience, promoting resilience. Mol. Psychiatry 23, 648657 (2018). [PubMed: 28070121]

142. Gunn BG et al. Dysfunctional astrocytic and synaptic regulation of hypothalamic glutamatergic transmission in a mouse model of early- life adversity: relevance to neurosteroids and programming of the stress response. J. Neurosci 33, 19534-19554 (2013). [PubMed: 24336719]

143. Eichenbaum $\mathrm{H}$ The role of the hippocampus in navigation is memory. J. Neurophysiol 117, 17851796 (2017). [PubMed: 28148640]

144. Wixted JT et al. Coding of episodic memory in the human hippocampus. Proc. Natl Acad. Sci. USA 115, 1093-1098 (2018). [PubMed: 29339476]

145. Squire LR, Genzel L, Wixted JT \& Morris RG Memory consolidation. Cold Spring Harb. Perspect. Biol 7, a021766 (2015). [PubMed: 26238360]

146. Zhang J et al. Mapping postnatal mouse brain development with diffusion tensor microimaging. Neuroimage 26, 1042-1051 (2005). [PubMed: 15961044]

147. Nassar R et al. Gestational age is dimensionally associated with structural brain network abnormalities across development. Cereb. Cortex 29, 2102-2114 (2019). [PubMed: 29688290]

148. Hodge RD et al. Tbr2 expression in Cajal-Retzius cells and intermediate neuronal progenitors is required for morphogenesis of the dentate gyrus. J. Neurosci 33, 4165-4180 (2013). [PubMed: 23447624]

149. Nakahira E \& Yuasa S Neuronal generation, migration, and differentiation in the mouse hippocampal primoridium as revealed by enhanced green fluorescent protein gene transfer by means of in utero electroporation. J. Comp. Neurol 483, 329-340 (2005). [PubMed: 15682392]

150. Kehoe P \& Bronzino JD Neonatal stress alters LTP in freely moving male and female adult rats. Hippocampus 9, 651-658 (1999). [PubMed: 10641758] 
151. Jackowski A et al. Early- life stress, corpus callosum development, hippocampal volumetrics, and anxious behavior in male nonhuman primates. Psychiatry Res. 192, 37-44 (2011). [PubMed: 21377844]

152. Lyons DM et al. Early life stress and inherited variation in monkey hippocampal volumes. Arch. Gen. Psychiatry 58, 1145-1151 (2001). [PubMed: 11735843]

153. Paus T in Handbook of Adolescent Psychology (eds. Lerner M \& Steinberg L). 95-115 (John Wiley \& Sons, 2009).

154. Braitenberg V \& Schüz A in Cortex: Statistics and Geometry of Neuronal Connectivity 93-98 (Springer, 1998).

155. Shansky RM \& Woolley CS Considering sex as a biological variable will be valuable for neuroscience research. J. Neurosci 36, 11817-11822 (2016). [PubMed: 27881768]

156. Eliot L \& Richardson SS Sex in context: limitations of animal studies for addressing human sex/ gender neurobehavioral health disparities. J. Neurosci 36, 11823-11830 (2016). [PubMed: 27881769]

157. Valentino RJ \& Bangasser DA Sex- biased cellular signaling: molecular basis for sex differences in neuropsychiatric diseases. Dialogues Clin. Neurosci 18, 385-393 (2016). [PubMed: 28179810]

158. Regev L \& Baram TZ Corticotropin releasing factor in neuroplasticity. Front. Neuroendocrinol 35, 171-179 (2014). [PubMed: 24145148]

159. Avena- Koenigsberger A, Misic B \& Sporns O Communication dynamics in complex brain networks. Nat. Rev. Neurosci 19, 17-33 (2017). [PubMed: 29238085]

160. Wisse LEM et al. A harmonized segmentation protocol for hippocampal and parahippocampal subregions: Why do we need one and what are the key goals? Hippocampus 27, 3-11 (2017). [PubMed: 27862600]

161. Driessen $\mathrm{M}$ et al. Magnetic resonance imaging volumes of the hippocampus and the amygdala in women with borderline personality disorder and early traumatization. Arch. Gen. Psychiatry 57, 1115 (2000). [PubMed: 11115325]

162. Bremner JD et al. Magnetic resonance imagingbased measurement of hippocampal volume in posttraumatic stress disorder related to childhood physical and sexual abuse - a preliminary report. Biol. Psychiatry 41, 23-32 (1997). [PubMed: 8988792]

163. Stein MB, Koverola C, Hanna C, Torchia MG \& McClarty B Hippocampal volume in women victimized by childhood sexual abuse. Psychol. Med 27, 951-959 (1997). [PubMed: 9234472]

164. Crossley NA et al. Imaging social and environmental factors as modulators of brain dysfunction: time to focus on developing non- Western societies. Biol. Psychiatry Cogn. Neurosci. Neuroimaging 4, 8-15 (2019). [PubMed: 30396768]

165. Lenze SN, Xiong C \& Sheline YI Childhood adversity predicts earlier onset of major depression but not reduced hippocampal volume. Psychiatry Res. Neuroimaging 162, 39-49 (2008).

166. Riem MME, Alink LRA, Out D, Van Ijzendoorn MH \& Bakermans- Kranenburg MJ Beating the brain about abuse: empirical and metaanalytic studies of the association between maltreatment and hippocampal volume across childhood and adolescence. Dev. Psychopathol 27, 507-520 (2015). [PubMed: 25997768]

167. Kim D-J et al. Childhood poverty and the organization of structural brain connectome. Neuroimage 184, 409-416 (2019). [PubMed: 30237035]

168. Buss C, Davis EP, Muftuler LT, Head K \& Sandman CA High pregnancy anxiety during midgestation is associated with decreased gray matter density in 6-9-year- old children. Psychoneuroendocrinology 35, 141-153 (2010). [PubMed: 19674845]

169. Hatfield T et al. 71: Magnetic resonance imaging (MRI) shows long term changes in brain structure in preterm infants exposed to chorioamnionitis. Am. J. Obstet. Gynecol 204, S41 (2011).

170. Sandman CA, Buss C, Head K \& Davis EP Fetal exposure to maternal depressive symptoms is associated with cortical thickness in late childhood. Biol. Psychiatry 77, 324-334 (2015). [PubMed: 25129235]

171. Curran MM, Sandman CA, Poggi Davis E, Glynn LM \& Baram TZ Abnormal dendritic maturation of developing cortical neurons exposed to corticotropin releasing hormone (CRH): 
insights into effects of prenatal adversity? PLOS ONE 12, e0180311 (2017). [PubMed: 28658297]

172. Hibar DP et al. Novel genetic loci associated with hippocampal volume. Nat. Commun 8, 13624 (2017). [PubMed: 28098162]

173. Feldman HM, Yeatman JD, Lee ES, Barde LHF \& Gaman- Bean S Diffusion tensor imaging: a review for pediatric researchers and clinicians. J. Dev. Behav. Pediatr 31, 346-356 (2010). [PubMed: 20453582]

174. Mori S \& Zhang J Principles of diffusion tensor imaging and its applications to basic neuroscience research. Neuron 51, 527-539 (2006). [PubMed: 16950152]

175. Sorg C et al. Selective changes of resting- state networks in individuals at risk for Alzheimer's disease. Proc. Natl Acad. Sci. USA 104, 18760-18765 (2007). [PubMed: 18003904]

176. Greicius MD, Srivastava G, Reiss AL \& Menon V Default- mode network activity distinguishes Alzheimer's disease from healthy aging: evidence from functional MRI. Proc. Natl Acad. Sci. USA 101, 4637-4642 (2004). [PubMed: 15070770]

177. Tahmasian $\mathrm{M}$ et al. Based on the network degeneration hypothesis: separating individual patients with different neurodegenerative syndromes in a preliminary hybrid PET/MR study. J. Nucl. Med 57, 410-415 (2016). [PubMed: 26585059]

178. Seeley WW, Crawford RK, Zhou J, Miller BL \& Greicius MD Neurodegenerative diseases target large- scale human brain networks. Neuron 62, 42-52 (2009). [PubMed: 19376066]

179. Pievani M, de Haan W, Wu T, Seeley WW \& Frisoni GB Functional network disruption in the degenerative dementias. Lancet Neurol. 10, 829-843 (2011). [PubMed: 21778116]

180. Landfield PW, McGaugh JL \& Lynch G Impaired synaptic potentiation processes in the hippocampus of aged, memory- deficient rats. Brain Res. 150, 85-101 (1978). [PubMed: 208716]

181. Riley JD et al. Network specialization during adolescence: hippocampal effective connectivity in boys and girls. Neuroimage 175, 402-412 (2018). [PubMed: 29649560]

182. Yassa MA, Muftuler LT \& Stark CEL Ultrahighresolution microstructural diffusion tensor imaging reveals perforant path degradation in aged humans in vivo. Proc. Natl Acad. Sci. USA 107, 12687-12691 (2010). [PubMed: 20616040]

183. Leal SL \& Yassa MA Neurocognitive aging and the hippocampus across species. Trends Neurosci. 38, 800-812 (2015). [PubMed: 26607684]

184. Kim D-J et al. Prenatal maternal cortisol has sexspecific associations with child brain network properties. Cereb. Cortex 27, 5230-5241 (2017). [PubMed: 27664961]

185. Luo L, Callaway EM \& Svoboda K Genetic dissection of neural circuits: a decade of progress. Neuron 98, 865 (2018). [PubMed: 29772206]

186. Roth BL DREADDs for neuroscientists. Neuron 89, 683-694 (2016). [PubMed: 26889809]

187. Kim CK, Adhikari A \& Deisseroth K Integration of optogenetics with complementary methodologies in systems neuroscience. Nat. Rev. Neurosci 18, 222-235 (2017). [PubMed: 28303019]

188. Lomvardas S \& Maniatis T Histone and DNA modifications as regulators of neuronal development and function. Cold Spring Harb. Perspect. Biol 8, a024208 (2016). [PubMed: 27371659]

189. Zocchi L \& Sassone- Corsi P Joining the dots: from chromatin remodeling to neuronal plasticity. Curr. Opin. Neurobiol 20, 432-440 (2010). [PubMed: 20471240]

190. Baker- Andresen D, Ratnu VS \& Bredy TW Dynamic DNA methylation: a prime candidate for genomic metaplasticity and behavioral adaptation. Trends Neurosci. 36, 3-13 (2013). [PubMed: 23041052]

191. Sweatt J The epigenetic basis of individuality. Curr. Opin. Behav. Sci 25, 51-56 (2019). [PubMed: 30560153]

192. Hwang J-Y, Aromolaran KA \& Zukin RS The emerging field of epigenetics in neurodegeneration and neuroprotection. Nat. Rev. Neurosci 18, 347-361 (2017). [PubMed: 28515491] 
193. McClelland S, Korosi A, Cope J, Ivy A \& Baram TZ Emerging roles of epigenetic mechanisms in the enduring effects of early- life stress and experience on learning and memory. Neurobiol. Learn. Mem 96, 79-88 (2011). [PubMed: 21338703]

194. Bale TL Epigenetic and transgenerational reprogramming of brain development. Nat. Rev. Neurosci 16, 332-344 (2015). [PubMed: 25921815]

195. Lipovich L et al. Activity- dependent human brain coding/noncoding gene regulatory networks. Genetics 192, 1133-1148 (2012). [PubMed: 22960213]

196. Szyf M Epigenetics, a key for unlocking complex CNS disorders? Therapeutic implications. Eur. Neuropsychopharmacol 25, 682-702 (2015). [PubMed: 24857313]

197. Turecki G The molecular bases of the suicidal brain. Nat. Rev. Neurosci 15, 802-816 (2014). [PubMed: 25354482]

198. Provencal $\mathrm{N}$ et al. The signature of maternal rearing in the methylome in rhesus macaque prefrontal cortex and T cells. J. Neurosci 32, 15626-15642 (2012). [PubMed: 23115197]

199. Provençal N \& Binder EB The effects of early life stress on the epigenome: from the womb to adulthood and even before. Exp. Neurol 268, 10-20 (2015). [PubMed: 25218020]

200. Mortazavi A, Williams BA, McCue K, Schaeffer L \& Wold B Mapping and quantifying mammalian transcriptomes by RNA- Seq. Nat. Methods 5, 621-628 (2008). [PubMed: 18516045]

201. Maze I et al. Analytical tools and current challenges in the modern era of neuroepigenomics. Nat. Neurosci 17, 1476-1490 (2014). [PubMed: 25349914]

202. Peixoto L et al. How data analysis affects power, reproducibility and biological insight of RNAseq studies in complex datasets. Nucleic Acids Res 43, 7664-7674 (2015). [PubMed: 26202970]

203. Verbitsky $M$ et al. Altered hippocampal transcript profile accompanies an age- related spatial memory deficit in mice. Learn. Mem 11, 253-260 (2004). [PubMed: 15169854]

204. Gray JD et al. Translational profiling of stressinduced neuroplasticity in the CA3 pyramidal neurons of BDNF Val66Met mice. Mol. Psychiatry 23, 904-913 (2018). [PubMed: 27956743]

205. Ahmadiyeh N, Slone- Wilcoxon JL, Takahashi JS \& Redei EE Maternal behavior modulates Xlinked inheritance of behavioral coping in the defensive burying test. Biol. Psychiatry 55, 10691074 (2004). [PubMed: 15158425]

206. Peña CJ et al. Early life stress confers lifelong stress susceptibility in mice via ventral tegmental area OTX2. Science 356, 1185-1188 (2017). [PubMed: 28619944]

207. Patterson KP et al. Enduring memory impairments provoked by developmental febrile seizures are mediated by functional and structural effects of neuronal restrictive silencing factor. J. Neurosci 37, 3799-3812 (2017). [PubMed: 28275159]

208. Schulmann A et al. Blocking NRSF function rescues spatial memory impaired by early- life adversity and reveals unexpected underlying transcriptional programs. SSRN Electron. J 10.2139/ssrn.3284454 (2018).

209. Gray JD, Kogan JF, Marrocco J \& McEwen BS Genomic and epigenomic mechanisms of glucocorticoids in the brain. Nat. Rev. Endocrinol 13, 661-673 (2017). [PubMed: 28862266]

210. Wang XD et al. Nectin-3 links CRHR1 signaling to stress- induced memory deficits and spine loss. Nat. Neurosci 16, 706-713 (2013). [PubMed: 23644483]

211. Roth TL, Lubin FD, Funk AJ \& Sweatt JD Lasting epigenetic influence of early- life adversity on the BDNF gene. Biol. Psychiatry 65, 760-769 (2009). [PubMed: 19150054]

212. Klengel T et al. Allele- specific FKBP5 DNA demethylation mediates gene-childhood trauma interactions. Nat. Neurosci 16, 33-41 (2013). [PubMed: 23201972]

213. Meaney MJ et al. Early environmental regulation of forebrain glucocorticoid receptor gene expression: implications for adrenocortical responses to stress. Dev. Neurosci 18, 49-72 (1996). [PubMed: 8840086]

214. Uchida $S$ et al. Early life stress enhances behavioral vulnerability to stress through the activation of REST4-mediated gene transcription in the medial prefrontal cortex of rodents. J. Neurosci 30, 15007-15018 (2010). [PubMed: 21068306] 
215. Bhansali P, Dunning J, Singer SE, David L \& Schmauss C Early life stress alters adult serotonin $2 \mathrm{c}$ receptor pre- mRNA editing and expression of the subunit of the heterotrimeric G- protein Gq. J. Neurosci 27, 1467-1473 (2007). [PubMed: 17287521]

216. Xu Z \& Taylor JA Genome- wide age- related DNA methylation changes in blood and other tissues relate to histone modification, expression and cancer. Carcinogenesis 35, 356-364 (2014). [PubMed: 24287154]

217. Alisch RS et al. Age- associated DNA methylation in pediatric populations. Genome Res. 22, 623-632 (2012). [PubMed: 22300631]

218. Florath I, Butterbach K, Müller H, Bewerunge-Hudler M \& Brenner H Cross- sectional and longitudinal changes in DNA methylation with age: an epigenome- wide analysis revealing over 60 novel age- associated CpG sites. Hum. Mol. Genet 23, 1186-1201 (2014). [PubMed: 24163245]

219. Horvath S DNA methylation age of human tissues and cell types. Genome Biol. 14, R115 (2013). [PubMed: 24138928]

220. Smith AK et al. DNA extracted from saliva for methylation studies of psychiatric traits: evidence tissue specificity and relatedness to brain. Am. J. Med. Genet. B Neuropsychiatr. Genet 168, 3644 (2015).

221. Tylee DS, Kawaguchi DM \& Glatt SJ On the outside, looking in: a review and evaluation of the comparability of blood and brain “-omes”. Am. J. Med. Genet. B Neuropsychiatr. Genet 162, 595-603 (2013).

222. Degerman S et al. Maintained memory in aging is associated with young epigenetic age. Neurobiol. Aging 55, 167-171 (2017). [PubMed: 28292535]

223. Marioni RE et al. The epigenetic clock is correlated with physical and cognitive fitness in the Lothian Birth Cohort 1936. Int. J. Epidemiol 44, 1388-1396 (2015). [PubMed: 25617346]

224. Levine ME et al. An epigenetic biomarker of aging for lifespan and healthspan. Aging 10, $573-$ 591 (2018). [PubMed: 29676998]

225. Horvath S \& Raj K DNA methylation- based biomarkers and the epigenetic clock theory of ageing. Nat. Rev. Genet 19, 371-384 (2018). [PubMed: 29643443]

226. Nemoda $\mathrm{Z}$ et al. Maternal depression is associated with DNA methylation changes in cord blood T lymphocytes and adult hippocampi. Transl. Psychiatry 5, e545 (2015). [PubMed: 25849984]

227. Peter CJ et al. DNA methylation signatures of early childhood malnutrition associated with impairments in attention and cognition. Biol. Psychiatry 80, 765-774 (2016). [PubMed: 27184921]

228. Eipel $\mathrm{M}$ et al. Epigenetic age predictions based on buccal swabs are more precise in combination with cell type- specific DNA methylation signatures. Aging 8, 1034-1048 (2016). [PubMed: 27249102]

229. Schwaiger M et al. Altered stress- induced regulation of genes in monocytes in adults with a history of childhood adversity. Neuropsychopharmacology 41, 2530-2540 (2016). [PubMed: 27091381]

230. Urdinguio RG et al. Longitudinal study of DNA methylation during the first 5 years of life. J. Transl. Med 14, 160 (2016). [PubMed: 27259700]

231. Jiang S et al. Intra- individual methylomics detects the impact of early- life adversity. Life Sci. Alliance 2, e201800204 (2019). [PubMed: 30936186]

232. Child and Adolescent Health Measurement Initiative. 2011-2012 national survey of children's health (CAHMI, 2013).

233. Hoynes H, Schanzenbach DW \& Almond D Longrun impacts of childhood access to the safety net. Am. Econ. Rev 106, 903-934 (2016).

234. Shaefer HL et al. A universal child allowance: a plan to reduce poverty and income instability among children in the United States. RSF 4, 22-42 (2018). [PubMed: 30246143]

235. Josselyn SA \& Frankland PW Infantile amnesia: a neurogenic hypothesis. Learn. Mem 19, 423433 (2012). [PubMed: 22904373]

236. Collie R \& Hayne H Deferred imitation by 6- and 9-month- old infants: more evidence for declarative memory. Dev. Psychobiol 35, 83-90 (1999). [PubMed: 10461122] 
237. Hayne H \& Herbert J Verbal cues facilitate memory retrieval during infancy. J. Exp. Child Psychol 89, 127-139 (2004). [PubMed: 15388302]

238. Evans GW \& Fuller- Rowell TE Childhood poverty, chronic stress, and young adult working memory: the protective role of self- regulatory capacity. Dev. Sci 16, 688-696 (2013). [PubMed: 24033574]

239. Kavanaugh BC, Dupont- Frechette JA, Jerskey BA \& Holler KA Neurocognitive deficits in children and adolescents following maltreatment: neurodevelopmental consequences and neuropsychological implications of traumatic stress. Appl. Neuropsychol. Child 6, 64-78 (2016). [PubMed: 27050166]

240. Tan HM, Wills TJ \& Cacucci F The development of spatial and memory circuits in the rat. Wiley Interdiscip. Rev. Cogn. Sci 8, e1424 (2016).

241. Alberini CM \& Travaglia A Infantile amnesia: a critical period of learning to learn and remember. J. Neurosci 37, 5783-5795 (2017). [PubMed: 28615475]

242. Avishai- Eliner S Stressed- out, or in (utero)? Trends Neurosci. 25, 518-524 (2002). [PubMed: 12220880]

243. Short AK, Maras PM, Pham AL, Ivy AS \& Baram TZ Short- term block of CRH receptor in adults mitigates age- related memory impairments provoked by early- life adversity. bioRxiv 10.1101/714451 (2019).

244. Werker JF \& Hensch TK Critical periods in speech perception: new directions. Annu. Rev. Psychol 66, 173-196 (2015). [PubMed: 25251488]

245. Sun $\mathrm{H}$ et al. Early seizures prematurely unsilence auditory synapses to disrupt thalamocortical critical period plasticity. Cell Rep. 23, 2533-2540 (2018). [PubMed: 29847785]

246. Takesian AE, Bogart LJ, Lichtman JW \& Hensch TK Inhibitory circuit gating of auditory criticalperiod plasticity. Nat. Neurosci 21, 218-227 (2018). [PubMed: 29358666]

247. Trachtenberg JT \& Stryker MP Rapid anatomical plasticity of horizontal connections in the developing visual cortex. J. Neurosci 21, 3476-3482 (2001). [PubMed: 11331376]

248. Amaral DG \& Dent JA Development of the mossy fibers of the dentate gyrus: I. A light and electron microscopic study of the mossy fibers and their expansions. J. Comp. Neurol 195, 51-86 (1981). [PubMed: 7204652]

249. Henze D, Urban N \& Barrionuevo G The multifarious hippocampal mossy fiber pathway: a review. Neuroscience 98, 407-427 (2000). [PubMed: 10869836]

250. Cotman CW, Berchtold NC \& Christie L-AA Exercise builds brain health: key roles of growth factor cascades and inflammation. Trends Neurosci. 30, 464-472 (2007). [PubMed: 17765329]

251. Nichol KE, Parachikova AI \& Cotman CW Three weeks of running wheel exposure improves cognitive performance in the aged Tg2576 mouse. Behav. Brain Res 184, 124-132 (2007). [PubMed: 17698211]

252. Nichol K, Deeny SP, Seif J, Camaclang K \& Cotman CW Exercise improves cognition and hippocampal plasticity in APOE epsilon4 mice. Alzheimers Dement. 5, 287-294 (2009). [PubMed: 19560099]

253. Segal SK, Cotman CW \& Cahill LF Exerciseinduced noradrenergic activation enhances memory consolidation in both normal aging and patients with amnestic mild cognitive impairment. J. Alzheimers Dis 32, 1011-1018 (2012). [PubMed: 22914593]

254. Guitar NA, Connelly DM, Nagamatsu LS, Orange JB \& Muir- Hunter SW The effects of physical exercise on executive function in communitydwelling older adults living with Alzheimer's- type dementia: a systematic review. Ageing Res. Rev 47, 159-167 (2018). [PubMed: 30102996]

255. Roberts CE, Phillips LH, Cooper CL, Gray S \& Allan JL Effect of different types of physical activity on activities of daily living in older adults: systematic review and meta- analysis. J. Aging Phys. Act 25, 653-670 (2017). [PubMed: 28181837]

256. Snigdha S, de Rivera C, Milgram NW \& Cotman CW Exercise enhances memory consolidation in the aging brain. Front. Aging Neurosci 6, 3 (2014). [PubMed: 24550824]

257. Baram TZ \& Bolton JL Parental smartphone use and children's mental outcomes: a neuroscience perspective. Neuropsychopharmacology 44, 239-240 (2019). [PubMed: 30181594] 
258. Galimberti I, Bednarek E, Donato F \& Caroni P EphA4 signaling in juveniles establishes topographic specificity of structural plasticity in the hippocampus. Neuron 65, 627-642 (2010). [PubMed: 20223199]

259. Donato F, Jacobsen RI, Moser M-B \& Moser EI Stellate cells drive maturation of the entorhinalhippocampal circuit. Science 355, eaai8178 (2017). [PubMed: 28154241]

260. Hong S, Dissing- Olesen L \& Stevens B New insights on the role of microglia in synaptic pruning in health and disease. Curr. Opin. Neurobiol 36, 128-134 (2016). [PubMed: 26745839]

261. Baram TZ, Donato F \& Holmes GL Construction and disruption of spatial memory networks during development. Learn. Mem 26, 206-218 (2019). [PubMed: 31209115]

262. Glynn LM \& Baram TZ The influence of unpredictable, fragmented parental signals on the developing brain. Front. Neuroendocrinol 53, 100736 (2019). [PubMed: 30711600]

263. Stanton ME \& Levine S Inhibition of infant glucocorticoid stress response: specific role of maternal cues. Dev. Psychobiol 23, 411-426 (1990). [PubMed: 2253818]

264. Suchecki D, Nelson DY, Oers H Van \& Levine, S. Activation and inhibition of the hypothalamicpituitary-adrenal axis of the neonatal rat: effects of maternal deprivation. Psychoneuroendocrinology 20, 169-182 (1995). [PubMed: 7899536]

265. Schmidt MV et al. The postnatal development of the hypothalamic- pituitary-adrenal axis in the mouse. Int. J. Dev. Neurosci 21, 125-132 (2003). [PubMed: 12711350]

266. Yi SJ \& Baram TZ Corticotropin- releasing hormone mediates the response to cold stress in the neonatal rat without compensatory enhancement of the peptide's gene expression. Endocrinology 135, 2364-2368 (1994). [PubMed: 7988418]

267. Dent GW, Smith MA \& Levine S Rapid induction of corticotropin- releasing hormone gene transcription in the paraventricular nucleus of the developing rat. Endocrinology 141, 1593-1598 (2000). [PubMed: 10803566]

268. Bohacek J \& Mansuy IM in Epigenetics and Neuroendocrinology (eds. Spengler D \& Binder E) 79-119 (Springer, 2016).

269. Herringa R Commentary: Paediatric post- traumatic stress disorder from a neurodevelopmental network perspective: reflections on Weems et al. (2019). J. Child Psychol. Psychiatry 60, 409411 (2019). [PubMed: 30919480] 


\section{Box 1 |}

\section{Construction and disruption of brain circuits}

Complex behaviours involve coordinated activities of brain circuits that integrate signals at the molecular, cellular, synaptic and network levels ${ }^{135,136}$ (see the figure).

Neurological disorders can arise from dysfunction of specific brain circuits, which originates from genetic risk factors and environmental influences, the latter taking place particularly during sensitive developmental periods ${ }^{103,109}$. The general framework of brain circuits is laid out by orchestrated programmes of gene expression in presynaptic and postsynaptic neurons ${ }^{258}$. However, brain circuits are immature for most of the developmental epoch, and different brain circuits mature within distinct individual developmental periods, with sensory circuits typically preceding the networks that underlie cognitive brain functions ${ }^{101,259}$. Executive function circuits centred on the prefrontal cortex are considered to be among the last to mature ${ }^{101}$.

The maturation and refinement of brain circuits is characterized by the establishment of stable intercellular connections via activity-dependent synaptic maturation and pruning, and the integration and coordination of the emergent brain networks to drive behaviour. Environment-derived sensory signals influence the development of sensory brain circuits; for example, light and visual patterns are required for the establishment of a normally functioning visual circuit ${ }^{137,247}$, via microglia-mediated pruning of 'extraneous' synapses ${ }^{104}$. This critical maturational process takes place during a defined sensitive period during the first few weeks of life in the rodent ${ }^{104,260}$, and an analogous sound and tone dependent process takes place in the maturation of auditory circuits ${ }^{246}$. Missing or aberrant signals from the environment are thought to drive aberrant maturation of these sensory brain circuits, resulting in persistently aberrant connectivity and function that is difficult to reverse beyond the 'plastic' sensitive period ${ }^{246,261}$. We propose that similar principles apply to the maturation of the brain circuits that underlie cognitive functions, including memory. The appropriate maturation of these circuits requires predictable and consistent signals during the first few years of life ${ }^{11,262}$. Unpredictable and fragmented environmental signals might disrupt this process, leading to cognitive problems during development, adult life and/or ageing. 


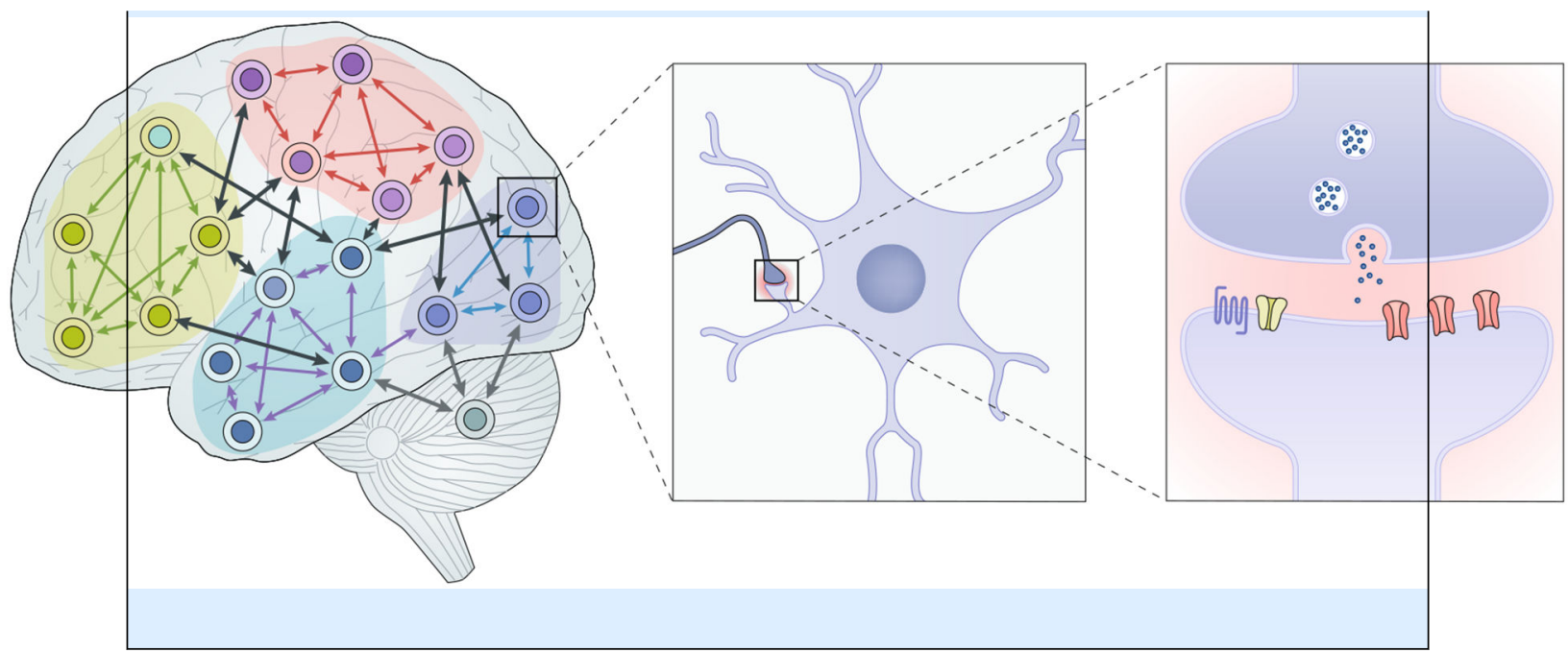




\section{Box 2}

\section{Adversity and the brain: evolving concepts}

Concepts regarding the influence of early-life adversity on brain function have evolved over the years. The three main phases of thinking on this topic are outlined below.

\section{no effects of stress on the brain}

Historically, in writings from the 1950s to the 1980s, the brain was considered to be immune to the effects of stress, possibly to provide protection from the traumatic effects of birth ${ }^{263-267}$.

\section{plasticity and epigenetics}

Over the next two decades, the profound and enduring effects of prenatal and postnatal adversity on brain function came to be recognized. The idea that persistent cellular consequences of adversity might persist throughout the lifetime of the individual and might even be transmitted across generations via epigenetic mechanisms also emerged during this phase of thinking $109,188,194,268$. Which brain cells are influenced, and how adversity signals reach specific neuronal populations was not yet clear at this time ${ }^{265-267}$.

\section{brain circuit maturation during sensitive periods}

During the past decade, the circuit organization of the brain and sensitive periods in the maturation of brain circuits via synaptic strengthening and pruning have come to be recognized ${ }^{103,106,240,259}$. These concepts are being applied to the effects of environmental signals, including adversity, on circuit maturation and function ${ }^{57,104,112,134,184,185,262,269}$. 


\section{Key points}

- A strong association exists between neurocognitive disorders and early-life adversity, and experimental animal models support a causal relationship, in addition to the critical effects of genetics and gene-environment interactions.

- The emotional aspects of adversity, including unpredictability of environmental and parental signals, most profoundly influence cognitive outcomes.

- Mechanistically, early-life adversity might disrupt the normal maturation of the brain circuits that underlie cognitive functions by modulating synaptic maturation and pruning.

- Novel cross-species imaging and epigenomic technologies hold promise for identifying mechanisms, biomarkers and mechanism-based preventive approaches and interventions. 


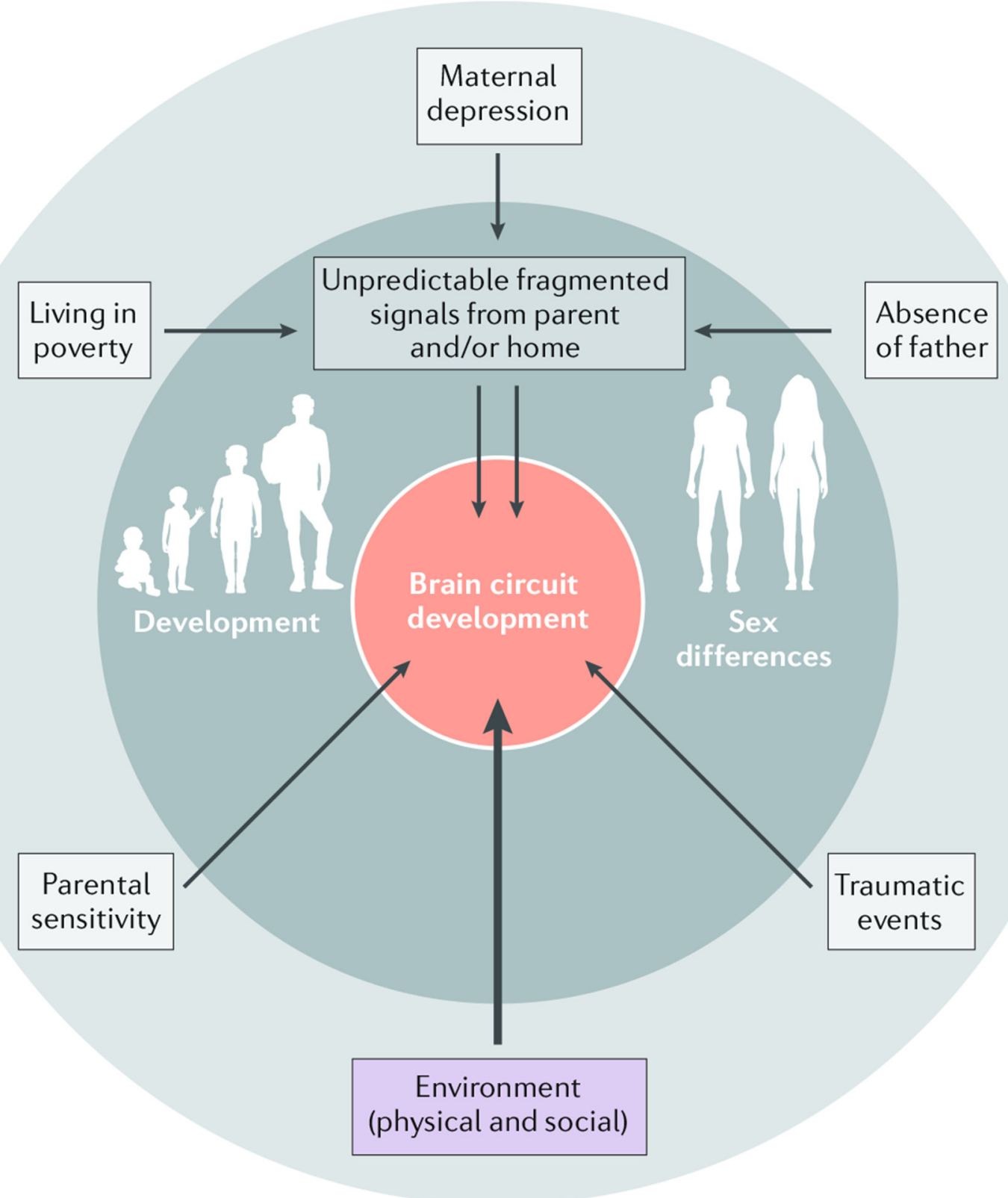

Fig. 1 . Do aberrant patterns of environmental signals to the developing brain constitute earlylife adversity?

This novel conceptual model, which incorporates emerging information from humans and experimental models $11,49,64,92$, centres on the prenatal and early postnatal epochs of human development and the maturation of brain circuits. The width of the arrows denotes the strength of influence. Sensory brain circuits, including visual and auditory networks, require patterned sensory signals (light and sound) for proper strengthening and pruning of synapses and, hence, formation of functional circuits. We posit that the same principle applies to cognitive circuits. Maturation of these circuits might require predictable and consistent sequences of environmental signals from the mother during late prenatal and early neonatal periods. Aberrant signals from the parent or environment represent a potential pathway or 
mechanism through which numerous aspects of early-life adversity (outer circle) modulate the maturation of structural and functional brain circuits that underlie cognition and complex behaviours. The impact of those exposures depends on age, sex and developmental stages during which the exposure occurs and the age at which assessments are conducted. In addition to being a potential mediator of established early-life risk factors for neurological and psychiatric diseases, fragmented or unpredictable patterns of parental and environmental signals could exert direct influences on the developing brain by modulating brain circuit maturation, leading to cognitive deficits ${ }^{64}$. 
a
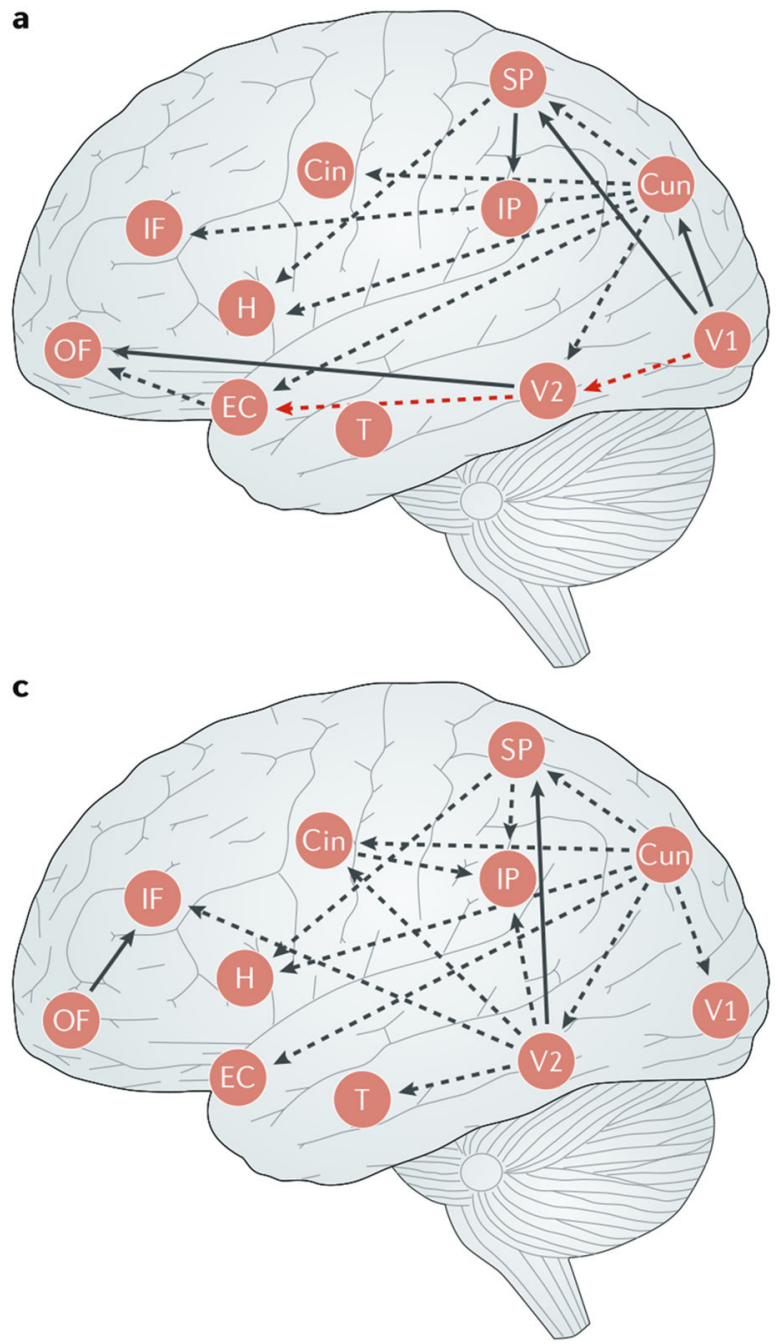

b

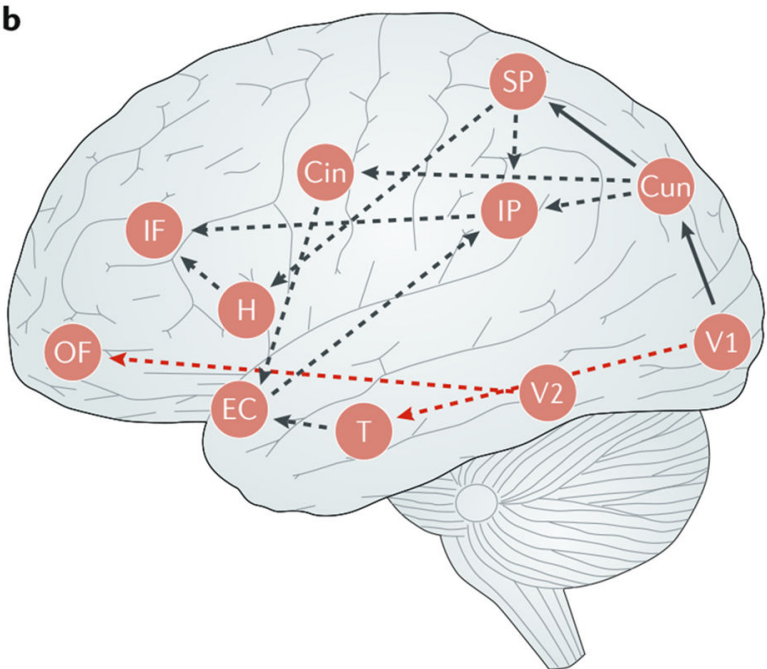

d

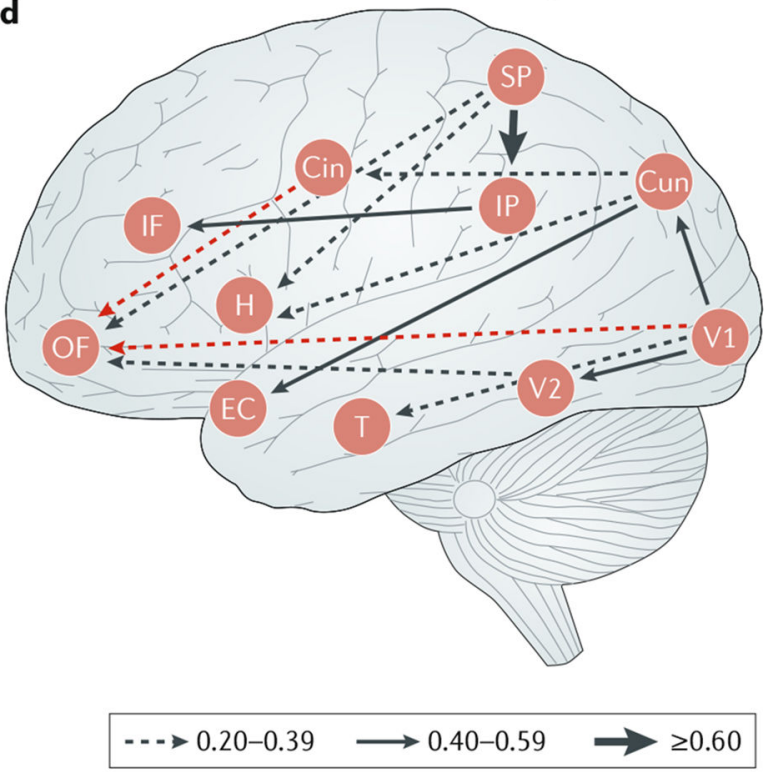

Fig. 2 |. Connectomic analysis reveals sex-specific development and maturation of brain circuits. MRI-based connectivity analysis in young girls (part a), older girls (part b), young boys (part c) and older boys (part d). Connections are presented by effective connectivity strength: low (0.20-0.39), medium (0.40-0.59) and high ( $\searrow 0.60)$; black arrows are positive effective connections, red arrows are negative effective connections. The orbitofrontal (OF) cortex, a major node that undergoes maturation during adolescence, seems to develop differently in boys and girls. For example, connections from primary visual areas (V1) to the $\mathrm{OF}$ are present in younger but not older girls and in older but not younger boys. Such differential patterns of development must be taken into consideration when assessing the effects of early-life adversity on brain development ${ }^{269}$. The patterns of connectivity are notable for relatively high density and posterior distribution in younger boys and an anteriorly shifted connectivity in older boys. Younger girls show an anterior-posterior distribution of connectivity in resembling that of older boys, but with more balanced distribution, and older girls exhibit an anteriorly shifted pattern of connectivity with overall 
lower density. Cin, cingulate cortex; Cun, cuneus/precuneus; EC, entorhinal cortex; H, hippocampus; IF, inferior frontal cortex; IP, inferior parietal cortex; SP, superior parietal cortex; T, temporal association cortex; V2, secondary visual cortex. Adapted with permission from $\mathrm{REF}^{181}$, Elsevier. 